\title{
Effects of Wild Yam Root (Dioscorea villosa) Extract on the Gene Expression Profile of Triple-negative Breast Cancer Cells
}

\author{
ELIZABETH MAZZIO, ABDULAZIZ ALMALKI, SELINA F. DARLING-REED and KARAM F.A. SOLIMAN \\ College of Pharmacy and Pharmaceutical Sciences, Institute of Public Health, \\ Florida A\&M University, Tallahassee, FL, U.S.A.
}

\begin{abstract}
Background/Aim: Wild yam extract [Dioscorea villosa, (WYE)] is consistently lethal at low $I_{50}$ s across diverse cancer-lines in vitro. Unlike traditional anti-cancer botanicals, WYE contains detergent saponins which reduce oil-water interfacial tensions causing disintegration of lipid membranes and causing cell lysis, creating an interfering variable. Here, we evaluate WYE at sub-lethal concentrations in MDA-MB-231 triple-negative breast cancer (TNBC) cells. Materials and Methods: Quantification of saponins, membrane potential, lytic death and sub-lethal WYE changes in whole transcriptomic (WT) mRNA, miRNAs and biological parameters were evaluated. Results: WYE caused 346 differentially expressed genes (DEGs) out of 48,226 transcripts tested; where up-regulated DEGS reflect immune stimulation, TNF signaling, COX2, cytokine release and cholesterol/steroid biosynthesis. Down-regulated DEGs reflect losses in cell division cycle (CDC), cyclins (CCN), cyclin-dependent kinases $(C D K s)$, centromere proteins (CENP), kinesin family members (KIFs) and polo-like kinases (PLKS), which were in alignment with biological studies. Conclusion: Sub-lethal concentrations of WYE appear to evoke pro-inflammatory, steroid biosynthetic and cytostatic effects in TNBC cells.
\end{abstract}

This article is freely accessible online.

Correspondence to: Karam F.A. Soliman Florida A \& M University, College of Pharmacy and Pharmaceutical Sciences. Institute of Public Health, Room G 134 H New Pharmacy Building, 1415 ML King Blvd Tallahassee, FL 32307, U.S.A. Tel: +1 8505993306, email:karam.soliman@famu.edu and Selina Darling-Reed, Florida A \& M University, College of Pharmacy and Pharmaceutical Sciences, Institute of Public Health, Room G 134 H New Pharmacy Building, 1415 ML King Blvd Tallahassee, FL 32307, U.S.A. Tel: +18505993306, e-mail: selina.darling@famu.edu

Key Words: Immune stimulation, wild yam, Dioscorea, breast cancer, cell cycle.
Dioscorea villosa is a North American native plant within the genus Dioscorea, and the roots and rhizomes of this species are known as wild yam (1). This plant has been widely used as a botanical dietary supplement to treat menopause-related hot flashes, muscular cramps, arthritis, upset stomach, coughs, problems related to childbirth, and in cosmetic topical ointments (1). Research on the medicinal value of wild yam root extract (WYE) has shown evidence suggesting anticancer properties in particular for breast cancer and in both hormone receptor-positive and triplenegative breast cancers (TNBC), where it alters epigenetic 5-hydroxymethylcytosine DNA patterns, induces toxicity, halts cell cycle, inhibits fatty acid synthase and modifies the activity of estrogen and progesterone hormone receptors (1$5)$. Because TNBC is characterized by the lack of estrogen, progesterone, and human epidermal growth factor receptor 2 receptors, treatment options are limited, leading to highly aggressive metastatic cancers, with poor clinical outcomes in terms of treatment relapse and life expectancy. For this reason, a good deal of research has been focused on finding effective alternative treatments for TNBC, such as the case for WYE, which contains hundreds of constituent saponins such as deltonins, dioscoreavillosides, diarylheptanoids (6), diosgenin, and dioscin, the latter two alone can slow breast tumor growth, migration, deter stem cell phenotype and cause cell death in various models (7-11).

There is a unique element of saponin-rich plants, which vastly differs from most naturally derived plant-based chemotherapies like taxol (Taxus brevifolia), having inherent emulsification properties and a capacity to destroy fats on contact, including those housed within biological membranes $(12,13)$. The "on-contact" cell lytic nature of saponins was first observed in red blood cells (RBCs) in the 1920s, likened to taurocholic acid (12), which disrupts cholesterol or phosphatidylcholine rich triglycerides causing pore formation, micellular structures, lytic permeability, and cell death (13). Steroidal saponins in WYE, such as dioscin and diosgenin target phosphatidylcholine-rich membranes while triterpene saponins tend to destroy cholesterol-rich membranes (14-18); 
the former can induce membrane lytic destruction within minutes (19-21).

Given that WYE and those of the Dioscorea species, to our knowledge, are of the most consistently cytotoxic herbs in vitro across diverse cancer cell lines by saponification/lytic membrane-mediated lysis $(22,23)$, the question remains as to effects that are occurring at concentrations (sub-lethal) that precede saponin induced lytic membrane destruction. In this work, we evaluate whole transcriptomic patterns induced by WYE at sub-lethal concentrations in MDA-MB-231 triplenegative breast cancer (TNBC) cells, where both immune stimulation and cell-cycle ablation are confirmed.

\section{Materials and Methods}

Wild yam extract (WYE) preparation. Wild Yam powder was purchased from Mountain Rose Herbs (Eugene, OR, USA). A crude WYE was prepared by dissolving the powder in absolute ethanol at $50 \mathrm{mg} / \mathrm{ml}$, followed by vortexing and storage in the dark at $-20^{\circ} \mathrm{C}$. Serial dilutions of WYE were prepared in sterile HBSS.

Cell culture. MDA-MB-231 HTB-26 $6^{\mathrm{TM}}$ cells were purchased from ATCC. The cells were cultured in $75 \mathrm{~cm}^{2}$ flasks with high glucose [4,500 g/l] DMEM supplemented with $7 \%$ FBS and $100 \mathrm{U} / \mathrm{ml}$ penicillin $\mathrm{G}$ sodium $/ 100 \mu \mathrm{g} / \mathrm{ml}$ streptomycin sulfate. Cells were grown at $37^{\circ} \mathrm{C}$ in $95 \%$ atmosphere $5 \% \mathrm{CO}_{2}$ and sub-cultured every three to five days. Experimental studies involving monolayers were conducted in growth media (as described above) in 96 well plates or $75 \mathrm{~cm}^{2}$ flasks. Experimental cultures involving 3D spheroids were seeded in culture media, using low-adhesion spheroid forming 96 well plates, and pelleted by centrifugation at $1,800 \times g$ for $3 \mathrm{~min}$, daily for the first three days. The spheroids were grown at $37^{\circ} \mathrm{C}$ in $95 \%$ atmosphere $5 \% \mathrm{CO}_{2}$ for 7 days prior to experimental treatment. Changes in morphology and live-cell imaging with FDA were captured using an inverted fluorescence microscope.

Human cytokine antibody array. Human cytokine antibody arrays (Cat\# AAM-CYT-1000) (Raybiotech Inc, Peachtree Corners, GA, USA) were used to profile supernatant cytokine content. Briefly, antibody-coated array membranes were first incubated for $30 \mathrm{~min}$ with $1 \mathrm{ml}$ of blocking buffer. After $30 \mathrm{~min}$, the blocking buffer was decanted and replaced with $1 \mathrm{ml}$ supernatant. Supernatants were pre-diluted in sample buffer to $20 \%$ to detect signals in highly expressed control proteins. Membranes were allowed to incubate for $5 \mathrm{~h}$ with shaking. Membranes were then washed with the prepared washing buffer and then incubated with $1 \mathrm{ml}$ biotin-conjugated antibodies. After incubation, the mixture of biotin-conjugated antibodies was removed, and membranes were incubated with HRPconjugated streptavidin $(2 \mathrm{~h})$. Detection of chemiluminescent spots was captured on Quantity One software installed on a Bio-Rad Versadoc (Bio-rad, Hercules, CA, USA), followed by densitometry analysis using NIH Image J software, microarray analysis plug-in (24). Data was imported into Raybio software data analysis sheets for final analysis.

Membrane potential and live-cell imaging. Fluorescent live cell imaging was carried out using fluorescein diacetate (FDA), which detects both plasma membrane integrity and the presence of viable cells, which retain the esterase cleaved fluorescein product (25). Tetramethyl rhodamine, ethyl ester (TMRE), was used as a permeable fluorescent cation potentiometric dye that can determine mitochondrial membrane potential in live cells (26). The loss of membrane potential and cell viability with elevated levels of saponins were captured by fluorescent imaging using an inverted fluorescent microscope.

Cell viability and proliferation. For basic toxicity experiments, cells were equally plated in 96 well plates at $0.5 \times 10^{6}$ cells $/ \mathrm{ml}$. Resazurin (Alamar Blue) indicator dye was used to measure cell viability as an indicator of basic metabolic rate (27). Briefly, a working solution of resazurin $(0.5 \mathrm{mg} / \mathrm{ml})$ was prepared in sterile PBS; filter sterilized through a 0.2 -micron filter, added to the samples $[15 \%(\mathrm{v} / \mathrm{v})$ equivalent], and returned to the incubator for 2-6 h. Reduction of the dye by viable cells reduced the oxidized resazurin, yielding a bright red fluorescent intermediate resorufin quantified using a Synergy HTX multi-mode reader (Bio-Tek, Winooski, VT, USA) using the following settings: $530 \mathrm{~nm}$ (excitation)/590 nm (emission) filters. Cell proliferation assays were conducted over 6 days, where cells were equally plated in 96 well plates at $0.05 \times 10^{6} \mathrm{cells} / \mathrm{ml}$ in culture media in the absence or presence of a varying concentration of WYE.

Saponin foam test. In this study, the stable foaming properties of the saponins in WYE were tested and correlated to the cytotoxic effects of the yam extract. In brief, $500 \mathrm{mg}$ of wild yam root (powdered) was added to $10 \mathrm{ml}$ of sterile water $(50 \mathrm{mg} / \mathrm{ml})$ and boiled for $5 \mathrm{~min}$, followed by filtration through a 0.4 -micron mesh filter. Serial dilutions of the filtrate were prepared in sterile water (room temperature) in separate glass test tubes, which were stopped and shaken vigorously for about 30 seconds. Samples were allowed to stand for one-half $h$. Honeycomb froth indicated saponins, where images were captured, and the foam area quantified using Image $\mathbf{J}$ analysis software (20).

Microarray WT 2.1 human datasets. All cells were washed three times in ice-cold $\mathrm{HBSS}$, rapidly frozen, and stored at $-80^{\circ} \mathrm{C}$. Total RNA was isolated and purified using the Trizol/chloroform method. The quality was assessed, and concentration was equalized to 82 $\mathrm{ng} / \mu \mathrm{l}$ in nuclease-free water. Whole transcriptome analysis was conducted according to the GeneChip TM WT PLUS Reagent Manual for Whole Transcript (WT).

Expression arrays. Briefly, RNA was synthesized to the first-strand cDNA, then second-strand cDNA, followed by a subsequent transcription to cRNA. cRNA was purified and assessed for yield prior to 2nd cycle single-stranded cDNA synthesis, hydrolysis of RNA, and purification of 2 nd cycle single-stranded cDNA. cDNA was then quantified for yield and equalized to $176 \mathrm{ng} / \mathrm{ml}$. Subsequently, cDNA was fragmented, labeled, and hybridized onto the arrays prior to being subjected to fluidics and imaging using the Gene Atlas (Affymetrix, ThermoFisher Scientific). The array data quality control and initial processing from CEL to CHP files were conducted using an expression console, prior to data evaluation using the Affymetrix transcriptome analysis console, String Database (String Consortium 2020) and DAVID functional annotation microarray tools (28-30), $n=3$. The dataset has been deposited to NIH Gene Expression Omnibus located at: https://www.ncbi.nlm.nih.gov/geo/query/acc.cgi?acc=GSE180621.

ELISA for IL-8. Supernatants from MDA-MB-231 cells (Control vs. WYE Lo $15 \mu \mathrm{g} / \mathrm{ml}$ ) were collected and centrifuged at $1,000 \times g$ for 5 min at $4^{\circ} \mathrm{C}$. Specific ELISA was performed using IL-8 ELISA kit 


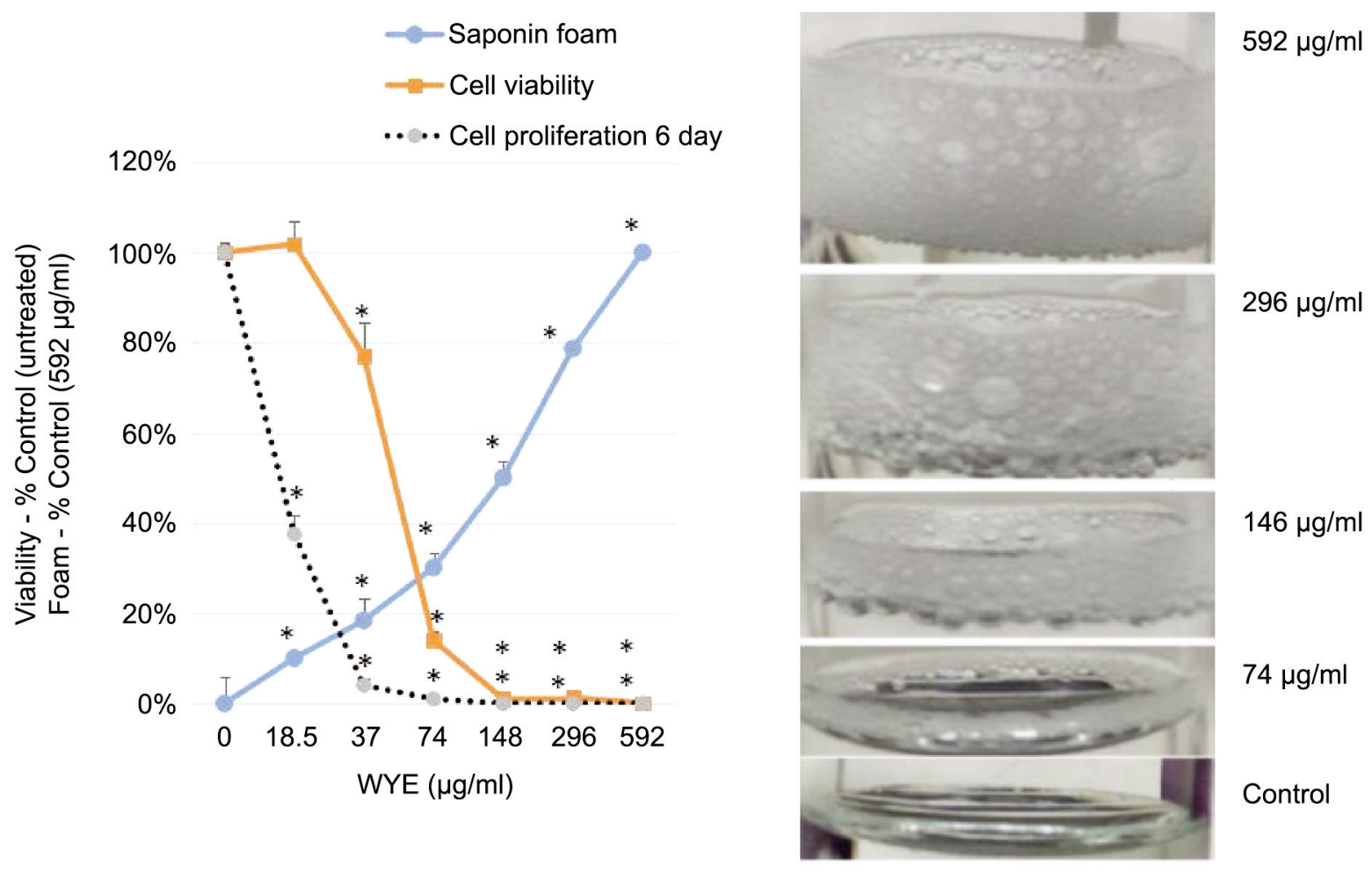

Figure 1. Cytotoxic and cytostatic effects related to saponin content of WYE in MDA-MB-231 cells. The data represent the mean $\pm S$.E.M, $n=4$ for cell viability (at $24 \mathrm{~h}$ ), cell proliferation (at 6 days) plotted as \% (untreated) controls and WYE saponin foam (where $592 \mu \mathrm{g} / \mathrm{ml}$ was set at $100 \%$ control), $n=3$. Significant differences between the controls and treatment groups were determined by a one way ANOVA, followed by a Tukey post hoc test ${ }^{*} p<0.05$. The gene chip icons, represent the 2 concentrations at which microarray analysis work was conducted representing WYE sublethal Low $(15 \mu \mathrm{g} / \mathrm{ml})$ and WYE sub-lethal High $(30 \mu \mathrm{g} / \mathrm{ml})$.

following manufacturer's instructions (Human IL-8/CXCL8 ELISA) (Millipore-Sigma, Saint Louis, MO, USA). The sample was diluted in buffer $20 \%$ supernatant/buffer, and $100 \mu \mathrm{l}$ of prepared supernatant from samples was added to 96 well plates pre-coated with the capture antibody. After incubation, $100 \mu \mathrm{l}$ of prepared biotinylated antibody mixture was added to each well. After $1 \mathrm{~h}$, the mixture was decanted, and $100 \mu \mathrm{l}$ streptavidin solution was placed in each well and incubated. Substrate reagent $(100 \mu \mathrm{l})$ was then added to each well for 30 min followed by a $50 \mu$ stop solution. Plates were read at $450 \mathrm{~nm}$ using a Biotek H.T.X. Synergy-multimode microplate reader.

Statistical analysis. Statistical analysis was performed for the basic studies using GraphPad Prism (version 3.0; Graph Pad Software Inc., San Diego, CA, USA). The significance of the difference between the groups was assessed using either a student's $t$-test or a one-way ANOVA followed by Tukey post hoc analysis.

\section{Results}

Both cytostatic and cytotoxic curves were generated over a dose-response of WYE, where saponins were quantified by a simple foam test (Figure 1). The data show a close correlation between foam and cell death, with the (anti-proliferative) cytostatic effects being in close proximity to/but slightly preceding sub-lethal concentrations of WYE. At this point, it is uncertain whether the loss of the cell cycle is related to basic cytotoxicity given the proximity of these curves, which will be further elucidated in this work. Next, the data show that greater saponin content in higher concentrations of WYE are associated with cell death, which coincides closely to damage to lipid membrane bio-layers. In Figure 2, we show basic fluorescent cell imaging of plasma membrane integrity/viability (left panel) and mitochondrial membrane (right) using fluorescent probes FDA and TMRE, respectively. The data show complete loss of both with greater saponin foam content in WYE. To determine if WYE saponins would also destroy a small 3D tumor spheroid, we evaluated cell survival (FDA) and morphological changes with increasing concentration of WYE (Figure 3). The data show spheroid tumors to be slightly more resistant to WYE, however, at concentrations exceeding $148 \mu \mathrm{g} / \mathrm{ml}$ there was near complete death of the entire spheroid.

For microarray studies, we chose to conduct experimentation at 2 sub-lethal concentrations denoted as Low $(15 \mu \mathrm{g} / \mathrm{ml})$; sublethal and High $(30 \mu \mathrm{g} / \mathrm{ml})$; sub-lethal/cusp of death (Figure 4). 
FDA
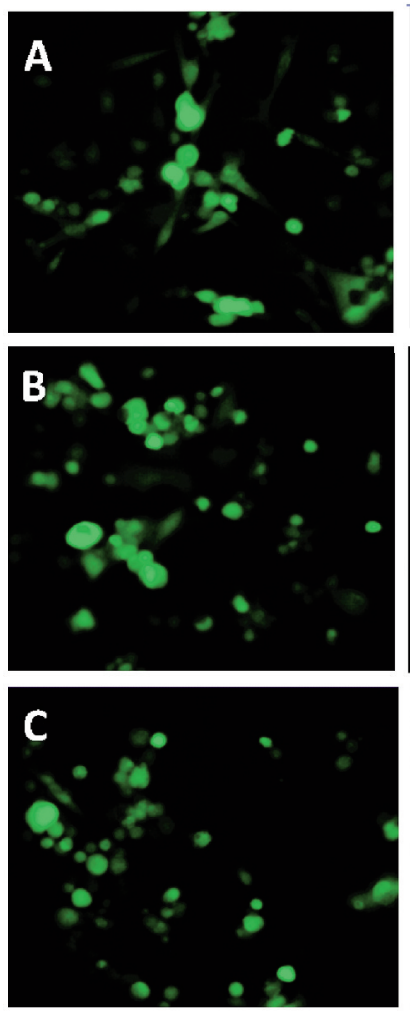

TMRE
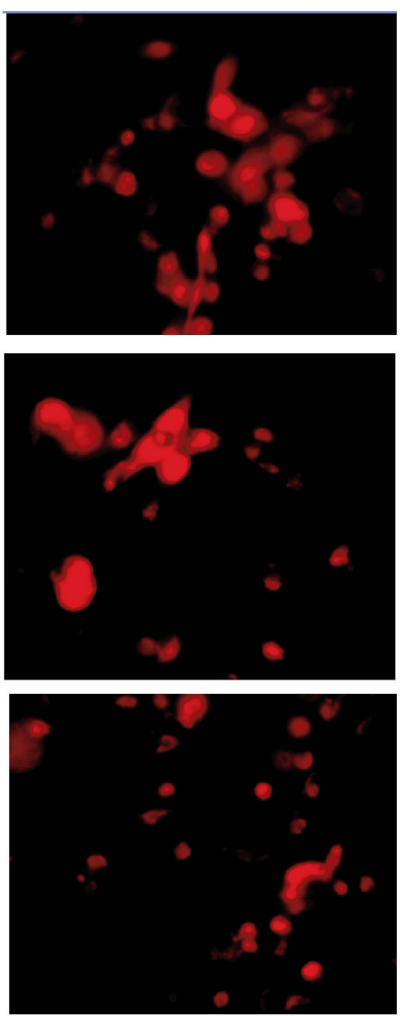

FDA

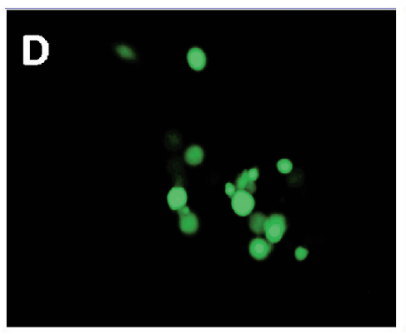

$\mathbf{E}$
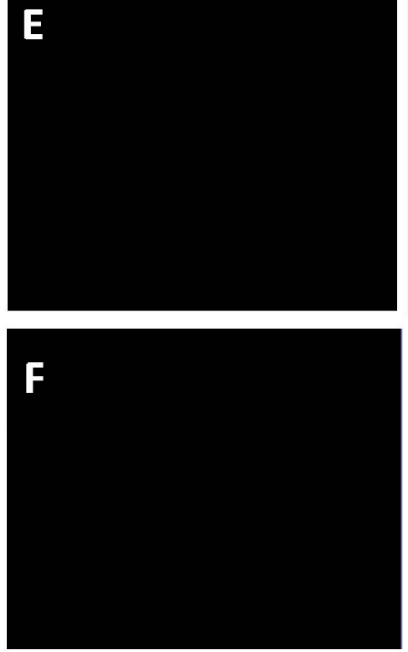

TMRE
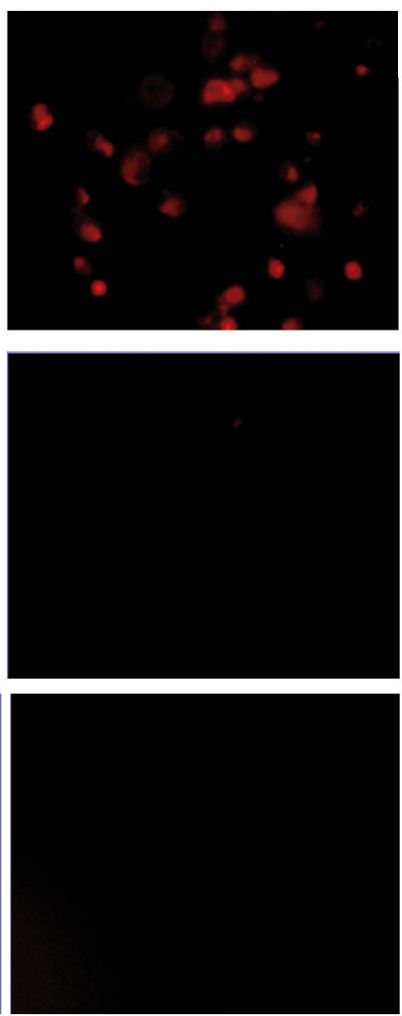

Figure 2. Effect of WYE on cell membrane potentials (plasma/viability) obtained with FDA (left panel) and mitochondrial TMRE (right panel). (A) Control, WYE Treatment (B) $18.5 \mu \mathrm{g} / \mathrm{ml},(C) 37 \mu \mathrm{g} / \mathrm{ml},(D) 74 \mu \mathrm{g} / \mathrm{ml},(E) 148 \mu \mathrm{g} / \mathrm{ml},(\mathrm{F}) 296 \mu \mathrm{g} / \mathrm{ml})$.

Cells for microarray studies were prepared in $75 \mathrm{~cm} 2$ flasks and monitored to ensure no morphological structure or attachment changes occurred over $24 \mathrm{~h}$ of treatment prior to cell pellet collection. Both cell pellets and supernatant were collected from the same samples and stored at $-80^{\circ} \mathrm{C}$. While we provide whole transcriptomic data on both sets, we focus the analysis within this article on only the WYE (low vs. control) data set. In both sets, less than $0.7 \%$ of the whole transcriptome showed differentially expressed genes (DEGs), with criteria set at $-2<\mathrm{x}>+2$-fold change, $p$-Value, and FDR $p$ Values $<0.05$. The data for DEGs in the WYE sub-lethal (low) $v s$. control groups are presented in Table I, with both sets, including sub-lethal WYE (high) vs. control provided at https://

www.ncbi.nlm.nih.gov/geo/query/acc.cgi?acc=GSE180621.

Using Stringdb, all down-regulated genes meeting criteria for WYE (low) were entered, and relational networks were identified (Figure 5). The data show a statistical loss in gene elements that transcribe for cell cycle and mitosis, showing a network FDR value for biological processes analysis (gene ontology) $p$-Value $<0.235 \mathrm{e}-83$. High significance for changes in the chromosome, cell division, DNA replication, and cross strand repair using local network cluster (STRING) also show FDR $p$-values up to $\mathrm{p}<4.48 \mathrm{e}-63$. All database platforms pickup up this differential as significant, including the Reactome and Kyoto Encyclopedia of Genes and Genomes (Kegg) pathways, where the latter was also found in the WIKIpathway report of Affymetrix/applied Biosystems transcriptome analysis console report (including up and down DEGs) (Figure 6). Similarly, stringdb analysis was performed on up-regulated DEGs for WYE (Low) (Figure 7 ), where most significant changes centered on steroid synthesis and cytokine signaling, specifically affecting the TNF-alpha pathway, changes also reflected in the component Kegg overlap map (Figure 8).

The supernatant of the samples matching the microarray was tested for the presence of cytokines using antibody arrays where the largest up-regulated differential DEG by WYE was for CXCL8/ IL-8, being observed in densitometry values within the anti-body array itself (Figure 9A,B), the Affymetrix microarray (Figure 10) and confirmed by Elisa (Figure 11). Figure 9A,B shows the relative comparison of cytokines released in the supernatant and the mRNA in cells, where the criteria for gene analysis was lowered to less than 2 -fold, with a significant $p$-Value $<0.05$ and no filter on FDR 

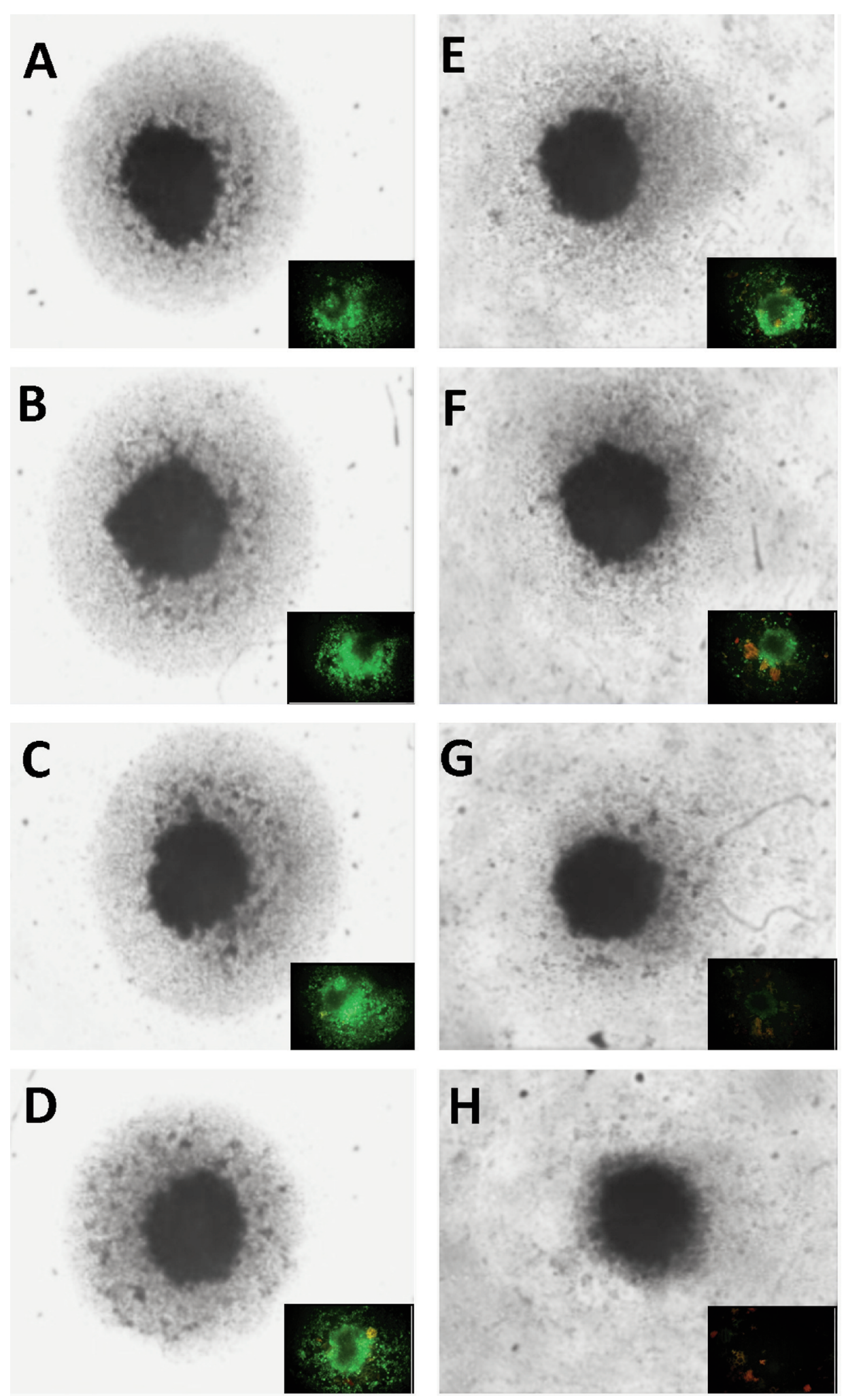

Figure 3. Effect of WYE on 3D tumor spheroids. Cell viability and morphological changes in MDA-MB-231 tumor spheroids with increasing concentration of WYE are shown. The data represent basic changes in spheroid structure (main image; black and white), with fluorescent FDA viable cell staining (green) in the lower left section of each main image. (A) Control, WYE Treatment (B) $4.62 \mu \mathrm{g} / \mathrm{ml}$, (C) $9.25 \mu \mathrm{g} / \mathrm{ml}$, (D) 18.5 $\mu \mathrm{g} / \mathrm{ml}$, (E) $37 \mu \mathrm{g} / \mathrm{ml},(\mathrm{F}) 74 \mu \mathrm{g} / \mathrm{ml}$, (G) $148 \mu \mathrm{g} / \mathrm{ml}$, (H) $296 \mu \mathrm{g} / \mathrm{ml}$. 


\section{Control vs. WYE (Low)}

* Control : 3 samples, WYE (Low): 3 samples

\author{
Filter Criter \\ ${ }^{*}$ Fold change: $>2$ or $<-2$ \\ $* p$-Value : $<0.05$ \\ * FDR $p$-Value: $<0.05$ \\ Total number of Genes: 48226 \\ * Genes Passed Filter Criteria :346 (.7\%) \\ *Up-Regulated: 166 \\ * Down-Regulated: 180
}

\section{WYE (Low) \\ Whole Transcriptome}

48,226 Transcripts Tested

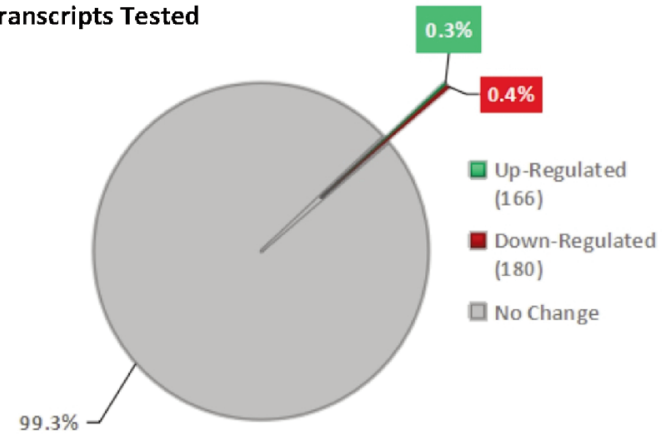

\section{Control vs. WYE (High)}

* Control : 3 samples, WYE (High): 2 samples

\section{Filter Criter}

*Fold change: $>2$ or $<-2$

$* p$-Value: $<0.05$

* FDR p-Value : $<0.05$

\author{
Total number of Genes: 48226 \\ * Genes Passed Filter Criteria :131 (.3\%) \\ *Up-Regulated: 89 \\ * Down-Regulated: 42
}

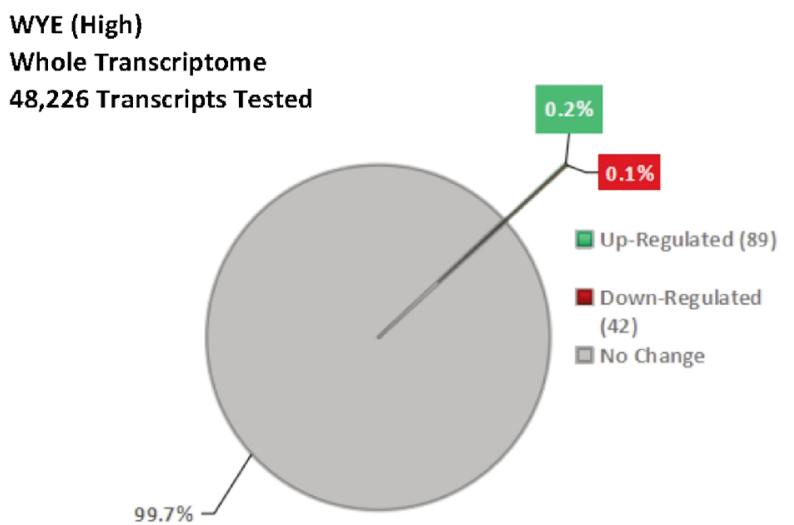

Figure 4. Microarray gene summary report. Overview of DEGs expressed when comparing controls (untreated) $n=3$ vs. WYE (Low, sub-lethal at $15 \mathrm{ug} / \mathrm{ml}) n=3$ or WYE (High, sub-lethal cusp of cell death at $30 \mathrm{ug} / \mathrm{ml}$ ). The data selection criteria were set at $-2<x>+2$ fold change, $p$-Value $<0.05$ and FDR p-Value <0.05.

$p$-Values. There was a high degree of matching values between proteins released in the supernatant and the mRNA transcription for those proteins in the same pellet sample. In summary, this provides an overall snapshot of the effects of WYE in MDA-MB-231 cells at sub-lethal concentrations.

\section{Discussion}

In this study, we evaluate the biological and transcriptomic effects of WYE on TNBC cells at sub-lethal concentrations, well below the point involving saponin-mediated cell lysis. WYE shows antiproliferative effects at sub-lethal concentration tantamount to severe downregulation of gene transcripts involved in mitosis and cell division, including transcripts of the following classes: cell division cycle (CDC), cysteine-rich protein 61, connective tissue growth factor, and nephroblastoma overexpressed (CCN), cyclindependent kinases (CDK), centromere proteins (CENPs), kinesin superfamily transcripts (KIFS), and polo-like kinases (PLK). These effects were concurrent with single gene up-regulation of the p21 gene CDKN1A, all of which are likely responsible for the observed cytostatic effects of WYE in a 6-day proliferation study. Our findings in this aspect support much of the existing literature for WYE and saponins from the Dioscorea species having the capacity to induce cell-cycle arrest $\left(\mathrm{G}_{2} / \mathrm{M}\right)$ across diverse cancer cell lines with observed downregulation of a similar list of cyclins and cell cycle regulatory transcripts (Cdc25C, Cdk1) (31-34).

While WYE was able to halt cell division effectively at low concentrations $(15 \mu \mathrm{g} / \mathrm{ml})$, the data in this work show an apparent rise in a series of genes that demarcate immune stimulation. As to the compounds responsible for these effects, they could be one or more of the known hundreds of compounds present in the root, such as diterpenes, phenolics, cyanidins, quinones, methyl parvifloside, trigofoenoside A1 , protodeltonin, deltonin, glucosidodeltonin, zingiberensis I, methylprotodioscin, zingiberensis, dioscin, prosapogenin, dioscoreavillosides $\mathrm{A}$ and $\mathrm{B}$, diarylheptanoids or possibly lipidated steroid saponins (6). 
Table I. Effects of WYE on the transcriptome in MDA-MB-231 cells. Selection criteria include greater than or less than 2 fold change and both pValues and FDR p-values <0.05. The data is presented as the effects of WYE on transcript by Fold Change, Gene Symbol, Gene Description, and significance.

Transcriptome changes: Control vs. WYE (Low $15 \mu \mathrm{g} / \mathrm{ml}$ ).

\begin{tabular}{|c|c|c|c|c|}
\hline Gene symbol & Description & Fold change & $p$-Value & FDR $p$-Value \\
\hline CXCL8 & Chemokine (C-X-C motif) ligand 8 & 9.09 & $3.79 \mathrm{E}-10$ & $1.83 \mathrm{E}-05$ \\
\hline KLF2 & Kruppel-like factor 2 & 7.82 & 4.67E-07 & $1.90 \mathrm{E}-03$ \\
\hline RHOB & Ras homolog fam. mem. B & 7.64 & $1.08 \mathrm{E}-09$ & $2.60 \mathrm{E}-05$ \\
\hline IL1A & Interleukin 1 alpha & 7.53 & $1.15 \mathrm{E}-05$ & $6.50 \mathrm{E}-03$ \\
\hline PTGS2 & Prostaglandin-endoperoxide synthase 2 [COX-2] & 7.01 & $1.59 \mathrm{E}-06$ & $2.80 \mathrm{E}-03$ \\
\hline HMOX1 & Heme oxygenase 1 & 5.79 & $1.75 \mathrm{E}-06$ & $2.80 \mathrm{E}-03$ \\
\hline NR1D1 & Nuclear receptor subfam. 1 , group D, mem. 1 & 5.45 & $5.65 \mathrm{E}-07$ & $2.10 \mathrm{E}-03$ \\
\hline HKDC1 & Hexokinase d.c. 1 & 5.36 & $5.50 \mathrm{E}-05$ & $1.29 \mathrm{E}-02$ \\
\hline GEM & GTP b.p overexpressed in skeletal muscle & 5.29 & $1.46 \mathrm{E}-07$ & $7.00 \mathrm{E}-04$ \\
\hline HMGCS1 & 3-hydroxy-3-methylglutaryl-CoA synthase 1 (soluble) & 5.28 & $9.36 \mathrm{E}-08$ & $5.00 \mathrm{E}-04$ \\
\hline INSIG1 & Insulin induced gene 1 & 5.25 & $2.24 \mathrm{E}-08$ & $3.00 \mathrm{E}-04$ \\
\hline ATF3 & Activating transcription factor 3 & 4.94 & 4.95E-06 & $5.00 \mathrm{E}-03$ \\
\hline DUSP10 & Dual specificity phosphatase 10 & 4.91 & $6.61 \mathrm{E}-06$ & $5.70 \mathrm{E}-03$ \\
\hline GDF15 & Growth differentiation factor 15 & 4.90 & $6.16 \mathrm{E}-07$ & $2.10 \mathrm{E}-03$ \\
\hline KDM7A & Lysine $(\mathrm{K})$-specific demethylase 7A & 4.88 & $8.70 \mathrm{E}-08$ & $5.00 \mathrm{E}-04$ \\
\hline EGR1 & Early growth response 1 & 4.74 & $1.99 \mathrm{E}-05$ & $8.00 \mathrm{E}-03$ \\
\hline TNFAIP3 & Tumor necrosis factor, alpha-induced protein 3 & 4.65 & $6.86 \mathrm{E}-07$ & $2.10 \mathrm{E}-03$ \\
\hline LOC105378662 & Uncharacterized LOC105378662; LOC105378663 & 4.32 & $7.74 \mathrm{E}-06$ & $5.70 \mathrm{E}-03$ \\
\hline TM4SF19 & TM4SF19; TCTEX1D2; TM4SF19-TCTEX1D2 & 4.26 & $2.18 \mathrm{E}-06$ & $3.00 \mathrm{E}-03$ \\
\hline RRAD & Ras-related associated with diabetes & 4.21 & $5.85 \mathrm{E}-08$ & $5.00 \mathrm{E}-04$ \\
\hline STC1 & Stanniocalcin 1 & 4.09 & $7.30 \mathrm{E}-08$ & $5.00 \mathrm{E}-04$ \\
\hline FBXO32 & F-box protein 32 & 3.86 & $1.00 \mathrm{E}-04$ & $1.80 \mathrm{E}-02$ \\
\hline KLHL24 & Kelch-like fam. mem. 24 & 3.85 & 1.62E-06 & $2.80 \mathrm{E}-03$ \\
\hline BACH1-IT2 & BACH1 intronic transcript 2 & 3.75 & $1.64 \mathrm{E}-05$ & 7.50E-03 \\
\hline CREBRF & CREB3 regulatory factor & 3.71 & $1.87 \mathrm{E}-05$ & $7.90 \mathrm{E}-03$ \\
\hline ZFPM2-AS1 & ZFPM2 antisense RNA 1 & 3.69 & $1.71 \mathrm{E}-05$ & $7.50 \mathrm{E}-03$ \\
\hline АВТВ2 & Ankyrin repeat and BTB (POZ) d.c. 2 & 3.64 & $2.89 \mathrm{E}-05$ & $9.70 \mathrm{E}-03$ \\
\hline LOC105373713 & Uncharacterized LOC105373713 & 3.55 & $6.22 \mathrm{E}-05$ & $1.33 \mathrm{E}-02$ \\
\hline YPEL2 & Yippee like 2 & 3.53 & 7.57E-07 & $2.10 \mathrm{E}-03$ \\
\hline EID3 & EP300 interacting inhibitor of differentiation 3 & 3.48 & $3.00 \mathrm{E}-04$ & $3.26 \mathrm{E}-02$ \\
\hline CDKN1A & Cyclin-dependent kinase inhibitor $1 \mathrm{~A}(\mathrm{p} 21, \mathrm{Cip} 1)$ & 3.46 & $6.19 \mathrm{E}-05$ & $1.33 \mathrm{E}-02$ \\
\hline ZNF114 & Zinc finger protein 114 & 3.40 & $9.59 \mathrm{E}-06$ & $6.00 \mathrm{E}-03$ \\
\hline PLEKHM1 & Pleckstrin homology, fam. M (w.RUN domain) mem. 1 & 3.37 & $6.46 \mathrm{E}-06$ & $5.70 \mathrm{E}-03$ \\
\hline SLC2A3 & Solute carrier fam. 2 (facilitated glucose), $\mathrm{m} 3$ & 3.37 & 8.34E-07 & $2.20 \mathrm{E}-03$ \\
\hline KLF7 & Kruppel-like factor 7 (ubiquitous) & 3.34 & $1.00 \mathrm{E}-04$ & $1.73 \mathrm{E}-02$ \\
\hline IL11 & Interleukin 11 & 3.33 & $3.00 \mathrm{E}-04$ & $3.09 \mathrm{E}-02$ \\
\hline KPNA7 & Karyopherin alpha 7 (importin alpha 8) & 3.24 & $9.69 \mathrm{E}-06$ & $6.00 \mathrm{E}-03$ \\
\hline SIK1 & Salt-inducible kinase 1 & 3.22 & $3.00 \mathrm{E}-04$ & $3.18 \mathrm{E}-02$ \\
\hline ZBTB10 & Zinc finger and BTB d.c. 10 & 3.21 & $4.00 \mathrm{E}-04$ & $3.96 \mathrm{E}-02$ \\
\hline IRAK2 & Interleukin 1 receptor associated kinase 2 & 3.19 & $2.00 \mathrm{E}-04$ & $2.15 \mathrm{E}-02$ \\
\hline KLF9 & Kruppel-like factor 9 & 3.18 & 8.04E-06 & $5.90 \mathrm{E}-03$ \\
\hline RASGEF1B & RasGEF domain fam. mem. 1B & 3.14 & $4.89 \mathrm{E}-06$ & $5.00 \mathrm{E}-03$ \\
\hline TMEM159 & Transmembrane protein 159 & 3.11 & $9.17 \mathrm{E}-06$ & $6.00 \mathrm{E}-03$ \\
\hline HIST1H2BD & Histone cluster $1, \mathrm{H} 2 \mathrm{bd}$ & 3.10 & $4.00 \mathrm{E}-04$ & $3.83 \mathrm{E}-02$ \\
\hline MIR4315-1 & MicroRNA 4315-1;2 PLEKHM1 & 3.09 & $1.06 \mathrm{E}-05$ & $6.30 \mathrm{E}-03$ \\
\hline CBLB & $\mathrm{Cbl}$ proto-oncogene $\mathrm{B}, \mathrm{E} 3$ ubiquitin protein ligase & 3.05 & $1.60 \mathrm{E}-05$ & $7.50 \mathrm{E}-03$ \\
\hline ICAM1 & Intercellular adhesion molecule 1 & 3.05 & $3.00 \mathrm{E}-04$ & $2.87 \mathrm{E}-02$ \\
\hline GFPT2 & Glutamine-fructose-6-phosphate transaminase 2 & 3.03 & $9.73 \mathrm{E}-06$ & $6.00 \mathrm{E}-03$ \\
\hline UAP1L1 & UDP-N-acetylglucosamine pyrophosphorylase 1 like 1 & 3.03 & $2.00 \mathrm{E}-04$ & $2.15 \mathrm{E}-02$ \\
\hline $\mathrm{NPC} 1$ & Niemann-Pick disease, type $\mathrm{C} 1$ & 3.01 & $1.90 \mathrm{E}-05$ & $7.90 \mathrm{E}-03$ \\
\hline GAB2 & GRB2-associated b.p 2 & 2.98 & $1.20 \mathrm{E}-05$ & $6.70 \mathrm{E}-03$ \\
\hline JUNB & Jun B proto-oncogene & 2.98 & $6.79 \mathrm{E}-05$ & $1.39 \mathrm{E}-02$ \\
\hline $\mathrm{DSC} 2$ & Desmocollin 2 & 2.97 & $8.50 \mathrm{E}-06$ & $5.90 \mathrm{E}-03$ \\
\hline MXD1 & MAX dimerization protein 1 & 2.96 & $5.60 \mathrm{E}-06$ & $5.20 \mathrm{E}-03$ \\
\hline
\end{tabular}


Table I. Continued

\begin{tabular}{|c|c|c|c|c|}
\hline Gene symbol & Description & Fold change & $p$-Value & FDR $p$-Value \\
\hline GABARAPL1 & GABA(A) receptor-associated protein like 1 & 2.95 & $1.39 \mathrm{E}-05$ & $7.20 \mathrm{E}-03$ \\
\hline FRZB & Frizzled-related protein & 2.93 & $1.38 \mathrm{E}-06$ & $2.80 \mathrm{E}-03$ \\
\hline TP53INP1 & Tumor protein p53 inducible nuclear protein 1 & 2.91 & $3.34 \mathrm{E}-07$ & $1.50 \mathrm{E}-03$ \\
\hline RRAGC & Ras-related GTP binding C & 2.89 & 2.07E-06 & $3.00 \mathrm{E}-03$ \\
\hline GRB10 & Growth factor receptor bound protein 10 & 2.87 & $1.74 \mathrm{E}-05$ & $7.60 \mathrm{E}-03$ \\
\hline KDM6B & Lysine (K)-specific demethylase 6B & 2.87 & $1.00 \mathrm{E}-04$ & $1.90 \mathrm{E}-02$ \\
\hline JUND & Jun $\mathrm{D}$ proto-oncogene & 2.84 & 2.87E-05 & $9.70 \mathrm{E}-03$ \\
\hline LSS & Lanosterol synthase & 2.84 & $2.00 \mathrm{E}-04$ & $2.19 \mathrm{E}-02$ \\
\hline TCP11L2 & T-complex 11 , testis-specific-like 2 & 2.82 & $1.75 \mathrm{E}-06$ & $2.80 \mathrm{E}-03$ \\
\hline HBP1 & HMG-box transcription factor 1 & 2.80 & $6.98 \mathrm{E}-05$ & $1.40 \mathrm{E}-02$ \\
\hline ABL2 & ABL proto-oncogene 2 , non-receptor tyrosine kinase & 2.75 & $2.28 \mathrm{E}-05$ & $8.50 \mathrm{E}-03$ \\
\hline FLCN; PLD6 & Golliculin; phospholipase D fam., mem. 6 & 2.75 & 4.37E-05 & $1.17 \mathrm{E}-02$ \\
\hline $\mathrm{BACH} 1$ & BTB and CNC homology 1, BLZTF 1 & 2.73 & $6.29 \mathrm{E}-05$ & $1.33 \mathrm{E}-02$ \\
\hline KLF6 & Kruppel-like factor 6 & 2.73 & $2.10 \mathrm{E}-05$ & $8.10 \mathrm{E}-03$ \\
\hline DENND2C & DENN/MADD d.c. $2 \mathrm{C}$ & 2.72 & $6.70 \mathrm{E}-06$ & $5.70 \mathrm{E}-03$ \\
\hline TRAF1 & TNF receptor-associated factor 1 & 2.71 & $1.00 \mathrm{E}-04$ & $2.03 \mathrm{E}-02$ \\
\hline MSMO1 & Methylsterol monooxygenase 1 & 2.70 & $1.56 \mathrm{E}-06$ & $2.80 \mathrm{E}-03$ \\
\hline PGM2L1 & Phosphoglucomutase 2-like 1 & 2.70 & $2.00 \mathrm{E}-04$ & $2.68 \mathrm{E}-02$ \\
\hline C3orf52 & Chromosome 3 open reading frame 52 & 2.69 & $2.00 \mathrm{E}-04$ & $2.23 \mathrm{E}-02$ \\
\hline LHFPL2 & Lipoma HMGIC fusion partner-like 2 & 2.69 & 7.62E-06 & $5.70 \mathrm{E}-03$ \\
\hline CXCL2 & Chemokine (C-X-C motif) ligand 2 & 2.68 & $2.00 \mathrm{E}-04$ & $2.75 \mathrm{E}-02$ \\
\hline FNIP1 & Folliculin interacting protein 1 & 2.68 & $7.67 \mathrm{E}-06$ & $5.70 \mathrm{E}-03$ \\
\hline TLR8-AS1 & TLR8 antisense RNA 1 & 2.67 & $1.00 \mathrm{E}-04$ & $1.86 \mathrm{E}-02$ \\
\hline PLIN2 & Perilipin 2 & 2.61 & 5.37E-06 & $5.10 \mathrm{E}-03$ \\
\hline SMOX & Spermine oxidase & 2.61 & $4.00 \mathrm{E}-04$ & $3.36 \mathrm{E}-02$ \\
\hline ZFYVE1 & Zinc finger, FYVE d.c. 1 & 2.59 & $6.51 \mathrm{E}-05$ & $1.36 \mathrm{E}-02$ \\
\hline FTH1 & Ferritin, heavy polypeptide 1 & 2.58 & 7.07E-06 & $5.70 \mathrm{E}-03$ \\
\hline USP53 & Ubiquitin specific peptidase 53 & 2.58 & 7.49E-06 & $5.70 \mathrm{E}-03$ \\
\hline TRPV3 & Transient receptor potential cation channel, sub-V, mem. 3 & 2.57 & $2.00 \mathrm{E}-04$ & $2.09 \mathrm{E}-02$ \\
\hline SLC43A2 & Solute carrier fam. 43 (amino acid), mem. 2 & 2.56 & $3.00 \mathrm{E}-04$ & $3.35 \mathrm{E}-02$ \\
\hline DDIT3 & DNA-damage-inducible transcript 3 & 2.54 & $4.22 \mathrm{E}-06$ & 4.60E-03 \\
\hline SOD2 & Superoxide dismutase 2 , mitochondrial & 2.53 & $5.88 \mathrm{E}-06$ & 5.30E-03 \\
\hline PIM1 & Pim-1 proto-oncogene, serine/threonine kinase & 2.52 & $2.60 \mathrm{E}-05$ & $9.30 \mathrm{E}-03$ \\
\hline CD83 & CD83 molecule & 2.51 & $4.00 \mathrm{E}-04$ & $3.93 \mathrm{E}-02$ \\
\hline HSPA1A; HSPA1B & Heat shock $70 \mathrm{kDa}$ protein $1 \mathrm{~A} ; 1 \mathrm{~B}$ & 2.50 & $1.85 \mathrm{E}-05$ & $7.90 \mathrm{E}-03$ \\
\hline CRYM-AS1 & CRYM antisense RNA 1 & 2.49 & $1.38 \mathrm{E}-05$ & $7.20 \mathrm{E}-03$ \\
\hline DUSP8 & Dual specificity phosphatase 8 & 2.49 & $7.99 \mathrm{E}-05$ & $1.48 \mathrm{E}-02$ \\
\hline SPDYA & Speedy/RINGO cell cycle regulator fam. mem. A & 2.47 & $2.45 \mathrm{E}-05$ & $8.90 \mathrm{E}-03$ \\
\hline KIAA1551 & KIAA1551 & 2.46 & 3.67E-05 & $1.07 \mathrm{E}-02$ \\
\hline ERN1 & Endoplasmic reticulum to nucleus signaling 1 & 2.45 & 7.36E-05 & $1.42 \mathrm{E}-02$ \\
\hline NPPA-AS1 & NPPA antisense RNA 1 & 2.45 & $3.12 \mathrm{E}-05$ & $1.00 \mathrm{E}-02$ \\
\hline PNRC1 & Proline-rich nuclear receptor coactivator 1 & 2.44 & $1.00 \mathrm{E}-04$ & $1.81 \mathrm{E}-02$ \\
\hline LOC101929125 & Uncharacterized LOC101929125 & 2.44 & $4.32 \mathrm{E}-06$ & $4.60 \mathrm{E}-03$ \\
\hline CSF1 & Colony stimulating factor 1 (macrophage) & 2.41 & $1.00 \mathrm{E}-04$ & $1.86 \mathrm{E}-02$ \\
\hline $\mathrm{ZC} 3 \mathrm{H} 12 \mathrm{C}$ & Zinc finger $\mathrm{CCCH}$-type containing $12 \mathrm{C}$ & 2.41 & $3.00 \mathrm{E}-04$ & $2.95 \mathrm{E}-02$ \\
\hline ITGB3 & Integrin beta 3 & 2.40 & $4.23 \mathrm{E}-05$ & $1.16 \mathrm{E}-02$ \\
\hline NOV & Nephroblastoma overexpressed & 2.40 & $2.00 \mathrm{E}-04$ & $2.09 \mathrm{E}-02$ \\
\hline TBC1D7 & TBC1 domain fam., mem. 7 & 2.40 & $2.70 \mathrm{E}-05$ & $9.40 \mathrm{E}-03$ \\
\hline HMGCR & 3-hydroxy-3-methylglutaryl-CoA reductase & 2.39 & $2.66 \mathrm{E}-06$ & $3.50 \mathrm{E}-03$ \\
\hline IL6R & Interleukin 6 receptor & 2.39 & $1.00 \mathrm{E}-04$ & $1.81 \mathrm{E}-02$ \\
\hline MMP1 & Matrix metallopeptidase 1 & 2.38 & $5.01 \mathrm{E}-06$ & $5.00 \mathrm{E}-03$ \\
\hline HSPA1B; HSPA1A & Heat shock $70 \mathrm{kDa}$ protein $1 \mathrm{~B} ; 1 \mathrm{~A}$ & 2.37 & $9.02 \mathrm{E}-05$ & $1.60 \mathrm{E}-02$ \\
\hline JUN & Jun proto-oncogene & 2.37 & $2.25 \mathrm{E}-05$ & $8.50 \mathrm{E}-03$ \\
\hline GAREM1 & GRB2 associated regulator of MAPK1 1 & 2.34 & $9.89 \mathrm{E}-05$ & $1.68 \mathrm{E}-02$ \\
\hline MIR616; DDIT3 & microRNA 616; DNA-damage-inducible transcript 3 & 2.33 & $4.72 \mathrm{E}-05$ & $1.22 \mathrm{E}-02$ \\
\hline PER1 & period circadian clock 1 & 2.33 & $2.00 \mathrm{E}-04$ & $2.61 \mathrm{E}-02$ \\
\hline NEU1 & Sialidase 1 (lysosomal sialidase) & 2.33 & $7.43 \mathrm{E}-05$ & $1.42 \mathrm{E}-02$ \\
\hline DHRS9 & dehydrogenase/reductase (SDR fam.) mem. 9 & 2.32 & $3.52 \mathrm{E}-05$ & $1.05 \mathrm{E}-02$ \\
\hline
\end{tabular}


Table I. Continued

\begin{tabular}{|c|c|c|c|c|}
\hline Gene symbol & Description & Fold change & $p$-Value & FDR $p$-Value \\
\hline LRRC37B & Leucine rich repeat containing $37 \mathrm{~B}$ & 2.32 & $4.00 \mathrm{E}-04$ & $3.74 \mathrm{E}-02$ \\
\hline ATP6V0D2 & ATPase, $\mathrm{H}+\mathrm{tr}$, lysosomal $38 \mathrm{kDa}, \mathrm{V} 0 \mathrm{su} . \mathrm{d} 2$ & 2.31 & $3.49 \mathrm{E}-05$ & $1.05 \mathrm{E}-02$ \\
\hline FOXC1 & Forkhead box $\mathrm{C} 1$ & 2.31 & $2.00 \mathrm{E}-04$ & $2.49 \mathrm{E}-02$ \\
\hline SQLE & Squalene epoxidase & 2.30 & 5.31E-05 & $1.28 \mathrm{E}-02$ \\
\hline JARID2 & Jumonji, AT rich interactive domain 2 & 2.29 & $2.00 \mathrm{E}-04$ & $2.27 \mathrm{E}-02$ \\
\hline UGDH & UDP-glucose 6-dehydrogenase & 2.29 & $1.25 \mathrm{E}-05$ & $6.80 \mathrm{E}-03$ \\
\hline LOC105379177 & Uncharacterized LOC105379177 & 2.29 & $6.29 \mathrm{E}-05$ & $1.33 \mathrm{E}-02$ \\
\hline LDLR & Low density lipoprotein receptor & 2.28 & $6.00 \mathrm{E}-05$ & $1.32 \mathrm{E}-02$ \\
\hline NFKBIA & NFK light polypeptide gene enh B-cells inhibitor, alpha & 2.28 & 4.29E-05 & $1.16 \mathrm{E}-02$ \\
\hline AHNAK2 & AHNAK nucleoprotein 2 & 2.27 & $2.00 \mathrm{E}-04$ & $2.68 \mathrm{E}-02$ \\
\hline CEBPB & CCAAT/enhancer b.p (C/EBP), beta & 2.27 & $8.36 \mathrm{E}-05$ & $1.53 \mathrm{E}-02$ \\
\hline DTNA & Dystrobrevin, alpha & 2.26 & $5.00 \mathrm{E}-04$ & 4.10E-02 \\
\hline SPAG9 & Sperm associated antigen 9 & 2.26 & $2.06 \mathrm{E}-05$ & $8.00 \mathrm{E}-03$ \\
\hline CYTH1 & Cytohesin 1 & 2.25 & $2.00 \mathrm{E}-04$ & $2.34 \mathrm{E}-02$ \\
\hline FAM102A & Fam. with sequence similarity 102, mem. A & 2.25 & $1.00 \mathrm{E}-04$ & $1.74 \mathrm{E}-02$ \\
\hline RNF19B & Ring finger protein $19 \mathrm{~B}$ & 2.25 & $4.00 \mathrm{E}-04$ & $3.72 \mathrm{E}-02$ \\
\hline ZBTB43 & Zinc finger and BTB d.c. 43 & 2.25 & 5.62E-05 & $1.30 \mathrm{E}-02$ \\
\hline IDI1 & Isopentenyl-diphosphate delta isomerase 1 & 2.24 & $8.46 \mathrm{E}-06$ & $5.90 \mathrm{E}-03$ \\
\hline CHD2 & Chromodomain helicase DNA b.p 2 & 2.23 & $6.97 \mathrm{E}-05$ & $1.40 \mathrm{E}-02$ \\
\hline IL6 & Interleukin 6 & 2.23 & $2.00 \mathrm{E}-04$ & $2.16 \mathrm{E}-02$ \\
\hline NDRG1 & $\mathrm{N}$-myc downstream regulated 1 & 2.23 & 3.94E-05 & $1.13 \mathrm{E}-02$ \\
\hline BHLHE40 & Basic helix-loop-helix fam., mem. e40 & 2.22 & $3.29 \mathrm{E}-05$ & $1.04 \mathrm{E}-02$ \\
\hline IER3 & Immediate early response 3 & 2.21 & $1.00 \mathrm{E}-04$ & $1.70 \mathrm{E}-02$ \\
\hline LIF & Leukemia inhibitory factor & 2.21 & $1.00 \mathrm{E}-04$ & $1.80 \mathrm{E}-02$ \\
\hline ZNF165 & Zinc finger protein 165 & 2.21 & $2.00 \mathrm{E}-04$ & $2.14 \mathrm{E}-02$ \\
\hline BTG1; LINC01619 & B-cell translocation gene 1, LINE RNA 1619 & 2.20 & $6.00 \mathrm{E}-04$ & $4.57 \mathrm{E}-02$ \\
\hline PMP22 & Peripheral myelin protein 22 & 2.19 & $1.65 \mathrm{E}-05$ & $7.50 \mathrm{E}-03$ \\
\hline THEMIS 2 & Thymocyte selection associated fam. mem. 2 & 2.19 & $8.30 \mathrm{E}-05$ & $1.53 \mathrm{E}-02$ \\
\hline CD55 & CD55 molecule, decay accelerating factor & 2.17 & $1.51 \mathrm{E}-05$ & $7.40 \mathrm{E}-03$ \\
\hline DUSP16 & Dual specificity phosphatase 16 & 2.17 & $1.00 \mathrm{E}-04$ & $1.70 \mathrm{E}-02$ \\
\hline SOX4 & SRY box 4 & 2.17 & $2.00 \mathrm{E}-04$ & $2.39 \mathrm{E}-02$ \\
\hline LOC105369949 & Uncharacterized LOC105369949 & 2.17 & $4.00 \mathrm{E}-04$ & $3.87 \mathrm{E}-02$ \\
\hline LOC105379695 & Uncharacterized LOC105379695 & 2.17 & $6.02 \mathrm{E}-05$ & $1.32 \mathrm{E}-02$ \\
\hline FZD8; MIR4683 & Frizzled class receptor 8; MicroRNA 4683 & 2.16 & $4.00 \mathrm{E}-04$ & $3.74 \mathrm{E}-02$ \\
\hline CLDN4 & Claudin 4 & 2.14 & 4.00E-04 & 3.64E-02 \\
\hline LINC-PINT & Long intergenic non-protein coding RNA, p53 & 2.13 & $2.00 \mathrm{E}-04$ & $2.17 \mathrm{E}-02$ \\
\hline IRS2 & Insulin receptor substrate 2 & 2.12 & $2.00 \mathrm{E}-04$ & $2.34 \mathrm{E}-02$ \\
\hline MCOLN3 & Mucolipin 3 & 2.12 & $5.50 \mathrm{E}-05$ & $1.29 \mathrm{E}-02$ \\
\hline STARD4 & StAR-related lipid transfer d.c. 4 & 2.12 & 4.09E-05 & $1.16 \mathrm{E}-02$ \\
\hline CTSL & Cathepsin L & 2.11 & $1.00 \mathrm{E}-04$ & $1.89 \mathrm{E}-02$ \\
\hline RHOF & Ras homolog fam. mem. F (in filopodia) & 2.11 & $6.00 \mathrm{E}-04$ & 4.93E-02 \\
\hline TIPARP & TCDD-inducible poly(ADP-ribose) polymerase & 2.11 & $2.00 \mathrm{E}-04$ & $2.17 \mathrm{E}-02$ \\
\hline STX3; OR10Y1P & Syntaxin 3 ; olfactory receptor, Fam. 10, subfam. Y, mem. 1pg & 2.10 & $2.00 \mathrm{E}-04$ & $2.43 \mathrm{E}-02$ \\
\hline PELI1 & Pellino E3 ubiquitin protein ligase 1 & 2.08 & $5.16 \mathrm{E}-05$ & $1.27 \mathrm{E}-02$ \\
\hline YOD1 & YOD1 deubiquitinase & 2.08 & $3.00 \mathrm{E}-04$ & $3.16 \mathrm{E}-02$ \\
\hline CYP51A1; LRRD1 & Cytochrome P450, f51, subfam. A, 1; LRR and DDC 1 & 2.07 & $3.16 \mathrm{E}-05$ & $1.00 \mathrm{E}-02$ \\
\hline IRF9 & Interferon regulatory factor 9 & 2.07 & $4.00 \mathrm{E}-04$ & $3.43 \mathrm{E}-02$ \\
\hline AGPAT4 & 1-acylglycerol-3-phosphate O-acyltransferase 4 & 2.05 & $2.34 \mathrm{E}-05$ & $8.60 \mathrm{E}-03$ \\
\hline HDAC9 & Histone deacetylase 9 & 2.05 & $3.00 \mathrm{E}-04$ & 2.97E-02 \\
\hline $\mathrm{ZCCHC} 14$ & Zinc finger, $\mathrm{CCHC}$ d.c. 14 & 2.05 & $6.00 \mathrm{E}-04$ & $4.95 \mathrm{E}-02$ \\
\hline JMJD1C & Jumonji d.c. $1 \mathrm{C}$ & 2.02 & $6.00 \mathrm{E}-04$ & $4.96 \mathrm{E}-02$ \\
\hline SQSTM1 & Sequestosome 1 & 2.02 & $1.00 \mathrm{E}-04$ & $1.89 \mathrm{E}-02$ \\
\hline KLF3 & Kruppel-like factor 3 (basic) & 2.01 & $3.00 \mathrm{E}-05$ & $9.80 \mathrm{E}-03$ \\
\hline TFPI2 & Tissue factor pathway inhibitor 2 & 2.01 & $9.34 \mathrm{E}-05$ & $1.64 \mathrm{E}-02$ \\
\hline AJUBA & Ajuba LIM protein & -2.00 & $5.00 \mathrm{E}-04$ & $3.97 \mathrm{E}-02$ \\
\hline KNTC1 & Kinetochore associated 1 & -2.00 & $1.00 \mathrm{E}-04$ & $1.70 \mathrm{E}-02$ \\
\hline POLR3B & Polymerase (RNA) III (DNA directed) polypeptide B & -2.00 & $2.00 \mathrm{E}-04$ & $2.25 \mathrm{E}-02$ \\
\hline SASS6 & SAS-6 centriolar assembly protein & -2.00 & $1.00 \mathrm{E}-04$ & $1.95 \mathrm{E}-02$ \\
\hline
\end{tabular}


Table I. Continued

\begin{tabular}{|c|c|c|c|c|}
\hline Gene symbol & Description & Fold change & $p$-Value & FDR $p$-Value \\
\hline HMGB2 & High mobility group box 2 & -2.01 & $3.00 \mathrm{E}-04$ & $3.26 \mathrm{E}-02$ \\
\hline BIRC5 & Baculoviral IAP repeat containing 5 & -2.02 & $7.84 \mathrm{E}-05$ & $1.46 \mathrm{E}-02$ \\
\hline GLMN & Glomulin, FKBP associated protein & -2.02 & $3.00 \mathrm{E}-04$ & $2.94 \mathrm{E}-02$ \\
\hline HIST1H2AJ & Histone cluster $1, \mathrm{H} 2 \mathrm{aj}$ & -2.02 & $3.00 \mathrm{E}-04$ & $2.87 \mathrm{E}-02$ \\
\hline ZNF738 & Zinc finger protein 738 & -2.02 & $5.76 \mathrm{E}-05$ & $1.31 \mathrm{E}-02$ \\
\hline CHRNA5 & Cholinergic receptor, nicotinic alpha 5 & -2.03 & 4.47E-05 & $1.18 \mathrm{E}-02$ \\
\hline NCAPD3 & Non-SMC condensin II complex su. D3 & -2.03 & $7.60 \mathrm{E}-05$ & $1.43 \mathrm{E}-02$ \\
\hline RMI1 & RecQ mediated genome instability 1 & -2.03 & $4.00 \mathrm{E}-04$ & $3.93 \mathrm{E}-02$ \\
\hline CDCA7L & Cell division cycle associated 7-like & -2.04 & $2.00 \mathrm{E}-04$ & $2.17 \mathrm{E}-02$ \\
\hline FAM111A & Fam. with sequence similarity 111 , mem. A & -2.04 & $9.96 \mathrm{E}-05$ & $1.68 \mathrm{E}-02$ \\
\hline FANCB & Fanconi anemia complementation group B & -2.04 & $2.00 \mathrm{E}-04$ & $2.44 \mathrm{E}-02$ \\
\hline LIN9 & Lin-9 DREAM MuvB core complex component & -2.04 & 7.89E-05 & $1.47 \mathrm{E}-02$ \\
\hline MYBL1 & V-myb avian myeloblastosis viral oncogene homolog-like 1 & -2.04 & $1.62 \mathrm{E}-05$ & $7.50 \mathrm{E}-03$ \\
\hline CEP192 & Centrosomal protein $192 \mathrm{kDa}$ & -2.06 & $5.00 \mathrm{E}-04$ & 4.23E-02 \\
\hline $\mathrm{CCNF}$ & Cyclin F & -2.07 & $3.44 \mathrm{E}-05$ & $1.05 \mathrm{E}-02$ \\
\hline STIL & SCL/TAL1 interrupting locus & -2.07 & $2.00 \mathrm{E}-04$ & $2.27 \mathrm{E}-02$ \\
\hline DHFR & Dihydrofolate reductase & -2.08 & $2.00 \mathrm{E}-04$ & $2.34 \mathrm{E}-02$ \\
\hline E2F8 & E2F transcription factor 8 & -2.08 & $9.40 \mathrm{E}-06$ & $6.00 \mathrm{E}-03$ \\
\hline RAD54B; FSBP & RAD54 homolog B; fibrinogen Silencer b.p & -2.08 & $2.00 \mathrm{E}-04$ & $2.34 \mathrm{E}-02$ \\
\hline SPRY1 & Sprouty RTK signaling antagonist 1 & -2.08 & $4.00 \mathrm{E}-04$ & $3.62 \mathrm{E}-02$ \\
\hline TPX2 & TPX2, microtubule-associated & -2.08 & $5.58 \mathrm{E}-05$ & $1.30 \mathrm{E}-02$ \\
\hline DSN1 & DSN1 homolog, MIS12 kinetochore complex component & -2.09 & $3.00 \mathrm{E}-04$ & $2.87 \mathrm{E}-02$ \\
\hline $\mathrm{CHAC} 2$ & ChaC, cation transport regulator homolog 2 (E. coli) & -2.10 & $3.44 \mathrm{E}-05$ & $1.05 \mathrm{E}-02$ \\
\hline PLK1 & Polo-like kinase 1 & -2.10 & 4.13E-05 & $1.16 \mathrm{E}-02$ \\
\hline PLK2 & Polo-like kinase 2 & -2.10 & $1.60 \mathrm{E}-05$ & $7.50 \mathrm{E}-03$ \\
\hline CASC5 & Cancer susceptibility candidate 5 & -2.11 & $2.00 \mathrm{E}-04$ & $2.56 \mathrm{E}-02$ \\
\hline CEP55 & Centrosomal protein $55 \mathrm{kDa}$ & -2.11 & $1.00 \mathrm{E}-04$ & $1.93 \mathrm{E}-02$ \\
\hline PRIMPOL & Primase and DNA directed polymerase & -2.11 & $5.00 \mathrm{E}-04$ & 4.01E-02 \\
\hline YEATS4 & YEATS d.c. 4 & -2.11 & $6.21 \mathrm{E}-05$ & $1.33 \mathrm{E}-02$ \\
\hline HSPA14 & Heat shock 70kDa protein 14 & -2.12 & $9.58 \mathrm{E}-05$ & $1.66 \mathrm{E}-02$ \\
\hline PRC1 & Protein regulator of cytokinesis 1 & -2.12 & $8.98 \mathrm{E}-05$ & $1.60 \mathrm{E}-02$ \\
\hline CENPQ & Centromere protein $\mathrm{Q}$ & -2.13 & $2.00 \mathrm{E}-04$ & $2.49 \mathrm{E}-02$ \\
\hline МТВР & MDM2 b.p & -2.13 & $2.00 \mathrm{E}-04$ & $2.16 \mathrm{E}-02$ \\
\hline RFC5 & Replication factor C su. 5 & -2.13 & $8.72 \mathrm{E}-05$ & $1.56 \mathrm{E}-02$ \\
\hline SLCO4A1 & Solute carrier organic anion transporter fam., mem. 4A1 & -2.13 & $1.00 \mathrm{E}-04$ & $2.02 \mathrm{E}-02$ \\
\hline SKA1 & Spindle and kinetochore associated complex su. 1 & -2.13 & $2.00 \mathrm{E}-04$ & $2.55 \mathrm{E}-02$ \\
\hline TICRR & TOPBP1-interacting checkpoint and replication regulator & -2.13 & $1.00 \mathrm{E}-04$ & $1.70 \mathrm{E}-02$ \\
\hline $\mathrm{EZH} 2$ & Enhancer of zeste 2 polycomb repressive complex 2 su. & -2.14 & $6.16 \mathrm{E}-05$ & $1.33 \mathrm{E}-02$ \\
\hline RAD51 & RAD51 recombinase & -2.14 & $2.19 \mathrm{E}-05$ & $8.30 \mathrm{E}-03$ \\
\hline STAMBPL1 & STAM b.p-like 1 & -2.14 & $4.40 \mathrm{E}-05$ & $1.17 \mathrm{E}-02$ \\
\hline WDHD1 & WD repeat and HMG-box DNA b.p 1 & -2.14 & $2.00 \mathrm{E}-04$ & $2.49 \mathrm{E}-02$ \\
\hline ZNF93 & Zinc finger protein 93 & -2.14 & $1.00 \mathrm{E}-04$ & $1.70 \mathrm{E}-02$ \\
\hline HAUS8 & HAUS augmin like complex su. 8 & -2.15 & $9.87 \mathrm{E}-05$ & $1.68 \mathrm{E}-02$ \\
\hline RBBP8 & Retinoblastoma b.p 8 & -2.15 & $5.02 \mathrm{E}-05$ & $1.25 \mathrm{E}-02$ \\
\hline RNU6-57P & RNA, U6 small nuclear 57, pseudogene & -2.15 & $4.00 \mathrm{E}-04$ & $3.80 \mathrm{E}-02$ \\
\hline ANLN & Anillin actin b.p & -2.16 & $8.51 \mathrm{E}-05$ & $1.55 \mathrm{E}-02$ \\
\hline FIGN & Fidgetin & -2.16 & $2.00 \mathrm{E}-04$ & $2.14 \mathrm{E}-02$ \\
\hline GSG2 & Germ cell associated 2 (haspin) & -2.16 & $1.00 \mathrm{E}-04$ & $1.89 \mathrm{E}-02$ \\
\hline HIST1H3B & Histone cluster $1, \mathrm{H} 3 \mathrm{~b}$ & -2.16 & 4.24E-05 & $1.16 \mathrm{E}-02$ \\
\hline CDC25A & Cell division cycle $25 \mathrm{~A}$ & -2.18 & 3.00E-04 & $3.16 \mathrm{E}-02$ \\
\hline $\mathrm{CCNB} 2$ & Cyclin B2 & -2.18 & $2.00 \mathrm{E}-04$ & $2.48 \mathrm{E}-02$ \\
\hline G2E3 & G2/M-phase specific E3 ubiquitin protein ligase & -2.18 & $6.00 \mathrm{E}-04$ & $4.94 \mathrm{E}-02$ \\
\hline KIF14 & Kinesin fam. mem. 14 & -2.18 & $2.00 \mathrm{E}-04$ & $2.56 \mathrm{E}-02$ \\
\hline TMPO & Thymopoietin & -2.18 & $4.43 \mathrm{E}-05$ & $1.17 \mathrm{E}-02$ \\
\hline PAK6; BUB1B & p21 protein $(\mathrm{Cdc} 42 / \mathrm{Rac})$-Activated kinase 6 ; BUB1 & -2.19 & 4.23E-05 & $1.16 \mathrm{E}-02$ \\
\hline RFC3 & Replication factor C su. 3 & -2.19 & $1.70 \mathrm{E}-05$ & $7.50 \mathrm{E}-03$ \\
\hline CCNE2 & Cyclin E2 & -2.20 & $7.59 \mathrm{E}-06$ & $5.70 \mathrm{E}-03$ \\
\hline PSIP1 & PC4 and SFRS 1 interacting protein 1 & -2.20 & $6.44 \mathrm{E}-05$ & $1.36 \mathrm{E}-02$ \\
\hline
\end{tabular}


Table I. Continued

\begin{tabular}{|c|c|c|c|c|}
\hline Gene symbol & Description & Fold change & $p$-Value & FDR $p$-Value \\
\hline RBL1 & Retinoblastoma-like 1 & -2.20 & $2.00 \mathrm{E}-04$ & $2.15 \mathrm{E}-02$ \\
\hline SMC4 & Structural maintenance of chromosomes 4 & -2.20 & $2.14 \mathrm{E}-05$ & $8.20 \mathrm{E}-03$ \\
\hline $\mathrm{XRCC} 2$ & $\mathrm{X}$-ray repair cdr in Chinese hamster cells 2 & -2.20 & $9.50 \mathrm{E}-05$ & $1.65 \mathrm{E}-02$ \\
\hline FANCI & Fanconi anemia complementation group I & -2.21 & $1.00 \mathrm{E}-04$ & $1.80 \mathrm{E}-02$ \\
\hline FAM216A & Fam. with sequence similarity 216 , mem. A & -2.22 & 3.00E-04 & $3.26 \mathrm{E}-02$ \\
\hline HELLS & Helicase, lymphoid-specific & -2.22 & $2.99 \mathrm{E}-05$ & $9.80 \mathrm{E}-03$ \\
\hline NEK2 & NIMA-related kinase 2 & -2.22 & $3.00 \mathrm{E}-04$ & $3.29 \mathrm{E}-02$ \\
\hline NCAPG & Non-SMC condensin I complex su. G & -2.22 & $5.94 \mathrm{E}-05$ & $1.32 \mathrm{E}-02$ \\
\hline $\mathrm{NCAPH}$ & Non-SMC condensin I complex su. H & -2.22 & $1.45 \mathrm{E}-05$ & 7.40E-03 \\
\hline SDPR & Serum deprivation response & -2.22 & $1.00 \mathrm{E}-04$ & $1.87 \mathrm{E}-02$ \\
\hline UBE2C & Ubiquitin-conjugating enzyme E2C & -2.22 & $1.00 \mathrm{E}-04$ & $2.05 \mathrm{E}-02$ \\
\hline LOC100507516 & Uncharacterized LOC100507516 & -2.22 & $2.00 \mathrm{E}-04$ & $2.44 \mathrm{E}-02$ \\
\hline CIT; MIR 1178 & Citron rho-interacting Ser/thrkinase; microRNA 1178 & -2.23 & $2.78 \mathrm{E}-05$ & $9.70 \mathrm{E}-03$ \\
\hline CENPI & Centromere protein I & -2.24 & 4.00E-04 & 3.62E-02 \\
\hline GINS1 & GINS complex su. 1 (Psf1 homolog) & -2.24 & $1.91 \mathrm{E}-05$ & $7.90 \mathrm{E}-03$ \\
\hline GINS4 & GINS complex su. 4 (Sld5 homolog) & -2.25 & $5.88 \mathrm{E}-06$ & $5.30 \mathrm{E}-03$ \\
\hline KIF20B & Kinesin fam. mem. 20B & -2.25 & $3.00 \mathrm{E}-04$ & $3.08 \mathrm{E}-02$ \\
\hline HIST2H2AB & Histone cluster 2, H2ab & -2.26 & $1.27 \mathrm{E}-05$ & $6.90 \mathrm{E}-03$ \\
\hline SLFN13 & Schlafen fam. mem. 13 & -2.26 & $3.54 \mathrm{E}-05$ & $1.05 \mathrm{E}-02$ \\
\hline UBE2T & Ubiquitin conjugating enzyme E2T & -2.26 & $2.40 \mathrm{E}-06$ & $3.20 \mathrm{E}-03$ \\
\hline PCNA-AS1 & PCNA antisense RNA 1 & -2.27 & 7.19E-05 & $1.42 \mathrm{E}-02$ \\
\hline TIMELESS & Timeless circadian clock & -2.27 & $6.12 \mathrm{E}-05$ & $1.33 \mathrm{E}-02$ \\
\hline MMS22L & MMS22-like, DNA repair protein & -2.29 & 2.94E-05 & $9.70 \mathrm{E}-03$ \\
\hline PARPBP & PARP1 b.p & -2.29 & $3.00 \mathrm{E}-04$ & $3.03 \mathrm{E}-02$ \\
\hline C18orf54 & Chromosome 18 open reading frame 54 & -2.30 & $9.02 \mathrm{E}-05$ & $1.60 \mathrm{E}-02$ \\
\hline CCDC138 & Coiled-coil d.c. 138 & -2.30 & $6.00 \mathrm{E}-04$ & $4.55 \mathrm{E}-02$ \\
\hline MKI67 & Marker of proliferation $\mathrm{Ki}-67$ & -2.30 & $1.14 \mathrm{E}-05$ & $6.50 \mathrm{E}-03$ \\
\hline VRK1; LINC00618 & Vaccinia related kinase 1; LIN RNA 618 & -2.30 & $1.00 \mathrm{E}-04$ & $1.81 \mathrm{E}-02$ \\
\hline ZNF215 & Zinc finger protein 215 & -2.30 & 2.63E-05 & $9.30 \mathrm{E}-03$ \\
\hline GMNN & Geminin, DNA replication inhibitor & -2.31 & $5.80 \mathrm{E}-05$ & $1.31 \mathrm{E}-02$ \\
\hline NUSAP1 & Nucleolar and spindle associated protein 1 & -2.31 & $3.97 \mathrm{E}-05$ & $1.13 \mathrm{E}-02$ \\
\hline CCNB1 & Cyclin B1 & -2.32 & 5.24E-05 & $1.27 \mathrm{E}-02$ \\
\hline RAD54L & RAD54-like (S. cerevisiae) & -2.32 & $5.00 \mathrm{E}-04$ & 4.16E-02 \\
\hline ARHGAP11A & Rho GTPase activating protein $11 \mathrm{~A}$ & -2.32 & $3.16 \mathrm{E}-05$ & $1.00 \mathrm{E}-02$ \\
\hline TMPO-AS1 & TMPO antisense RNA 1 & -2.32 & 5.44E-06 & $5.10 \mathrm{E}-03$ \\
\hline ASPM & Aabnormal spindle microtubule assembly & -2.33 & $2.00 \mathrm{E}-04$ & $2.17 \mathrm{E}-02$ \\
\hline ATAD2 & ATPase fam., AAA d.c. 2 & -2.34 & 7.06E-05 & $1.41 \mathrm{E}-02$ \\
\hline FOXM1 & Forkhead box M1 & -2.34 & 8.37E-05 & $1.53 \mathrm{E}-02$ \\
\hline FIGNL1 & Fidgetin-like 1 & -2.35 & $3.79 \mathrm{E}-05$ & $1.09 \mathrm{E}-02$ \\
\hline LOC 105376603 & Uncharacterized LOC105376603 & -2.35 & $6.61 \mathrm{E}-05$ & $1.37 \mathrm{E}-02$ \\
\hline $\mathrm{C} 1$ orf 112 & Chromosome 1 open reading frame 112 & -2.36 & $2.91 \mathrm{E}-05$ & $9.70 \mathrm{E}-03$ \\
\hline KIF18B & Kinesin fam. mem. $18 \mathrm{~B}$ & -2.36 & 3.59E-05 & $1.05 \mathrm{E}-02$ \\
\hline BLM & Bloom syndrome, RecQ helicase-like & -2.37 & 4.97E-05 & $1.25 \mathrm{E}-02$ \\
\hline KIF4A & Kinesin fam. mem. $4 \mathrm{~A}$ & -2.39 & $5.00 \mathrm{E}-04$ & 4.24E-02 \\
\hline MND1 & Meiotic nuclear divisions 1 & -2.39 & $1.30 \mathrm{E}-05$ & $6.90 \mathrm{E}-03$ \\
\hline NUF2 & NUF2, NDC80 kinetochore complex component & -2.39 & $5.00 \mathrm{E}-04$ & 4.01E-02 \\
\hline C5orf34 & Chromosome 5 open reading frame 34 & -2.40 & $5.60 \mathrm{E}-05$ & $1.30 \mathrm{E}-02$ \\
\hline CDKN3 & cyclin-dependent kinase inhibitor 3 & -2.41 & $9.46 \mathrm{E}-05$ & $1.65 \mathrm{E}-02$ \\
\hline FANCD2 & Fanconi anemia complementation group D2 & -2.41 & 7.18E-05 & $1.42 \mathrm{E}-02$ \\
\hline PLK4 & Polo-like kinase 4 & -2.41 & $2.00 \mathrm{E}-04$ & $2.17 \mathrm{E}-02$ \\
\hline BARD1 & BRCA1 associated RING domain 1 & -2.44 & $1.44 \mathrm{E}-05$ & $7.40 \mathrm{E}-03$ \\
\hline CENPE & Centromere protein $\mathrm{E}$ & -2.44 & $4.00 \mathrm{E}-04$ & $3.42 \mathrm{E}-02$ \\
\hline MAD2L1 & MAD2 mitotic arrest deficient-like 1 (yeast) & -2.44 & $2.00 \mathrm{E}-04$ & $2.17 \mathrm{E}-02$ \\
\hline SHCBP1 & SHC SH2-domain b.p 1 & -2.45 & $1.10 \mathrm{E}-05$ & $6.50 \mathrm{E}-03$ \\
\hline WDR76 & WD repeat domain 76 & -2.45 & $1.00 \mathrm{E}-04$ & $1.83 \mathrm{E}-02$ \\
\hline FBXO43 & F-box protein 43 & -2.46 & $4.96 \mathrm{E}-05$ & $1.25 \mathrm{E}-02$ \\
\hline CDC6 & Cell division cycle 6 & -2.47 & $2.00 \mathrm{E}-04$ & $2.61 \mathrm{E}-02$ \\
\hline ESPL1 & Extra spindle pole bodies like 1, separase & -2.47 & $5.09 \mathrm{E}-05$ & $1.26 \mathrm{E}-02$ \\
\hline
\end{tabular}


Table I. Continued

\begin{tabular}{|c|c|c|c|c|}
\hline Gene symbol & Description & Fold change & $p$-Value & FDR $p$-Value \\
\hline DEPDC1B & DEP d.c. $1 \mathrm{~B}$ & -2.48 & $1.00 \mathrm{E}-04$ & $2.00 \mathrm{E}-02$ \\
\hline HMMR & Hyaluronan-mediated motility receptor (RHAMM) & -2.48 & $3.00 \mathrm{E}-04$ & $3.09 \mathrm{E}-02$ \\
\hline KIFC1 & Kinesin fam. mem. C1 & -2.48 & 3.34E-05 & $1.04 \mathrm{E}-02$ \\
\hline RAD51AP1 & RAD51 associated protein 1 & -2.48 & $1.00 \mathrm{E}-04$ & $1.69 \mathrm{E}-02$ \\
\hline SPC24 & SPC24, NDC80 kinetochore complex component & -2.48 & $7.12 \mathrm{E}-06$ & $5.70 \mathrm{E}-03$ \\
\hline CENPU & Centromere protein $\mathrm{U}$ & -2.49 & $1.50 \mathrm{E}-05$ & $7.40 \mathrm{E}-03$ \\
\hline KIF11 & Kinesin fam. mem. 11 & -2.49 & $3.63 \mathrm{E}-05$ & $1.06 \mathrm{E}-02$ \\
\hline NEIL3 & Nei-like DNA glycosylase 3 & -2.49 & $8.28 \mathrm{E}-06$ & $5.90 \mathrm{E}-03$ \\
\hline FBXO5 & F-box protein 5 & -2.50 & 2.00E-04 & $2.48 \mathrm{E}-02$ \\
\hline KIF2C & Kinesin fam. mem. $2 \mathrm{C}$ & -2.50 & $1.06 \mathrm{E}-05$ & $6.30 \mathrm{E}-03$ \\
\hline CEP295 & Centrosomal protein $295 \mathrm{kDa}$ & -2.51 & $1.00 \mathrm{E}-04$ & $1.81 \mathrm{E}-02$ \\
\hline TOP2A & Topoisomerase (DNA) II alpha & -2.51 & $6.59 \mathrm{E}-05$ & $1.37 \mathrm{E}-02$ \\
\hline SUV39H2 & Suppressor of variegation 3-9 homolog 2 (Drosophila) & -2.52 & 2.00E-04 & $2.37 \mathrm{E}-02$ \\
\hline ARHGAP11B & Rho GTPase activating protein 11B & -2.54 & $1.05 \mathrm{E}-05$ & $6.30 \mathrm{E}-03$ \\
\hline DLGAP5 & Discs, large (Drosophila) homolog-associated protein 5 & -2.55 & $1.00 \mathrm{E}-04$ & $1.89 \mathrm{E}-02$ \\
\hline HMGN2 & High mobility group nucleosomal binding domain 2 & -2.55 & $1.00 \mathrm{E}-04$ & $1.81 \mathrm{E}-02$ \\
\hline ZGRF1 & Zinc finger, GRF-type containing 1 & -2.55 & 2.65E-05 & $9.30 \mathrm{E}-03$ \\
\hline TRIP13 & Thyroid hormone receptor interactor 13 & -2.57 & $1.00 \mathrm{E}-04$ & $1.93 \mathrm{E}-02$ \\
\hline BRIP1 & BRCA1 interacting protein C-terminal helicase 1 & -2.59 & $1.67 \mathrm{E}-05$ & $7.50 \mathrm{E}-03$ \\
\hline BUB1 & BUB1 mitotic checkpoint serine/threonine kinase & -2.59 & $2.01 \mathrm{E}-05$ & $8.00 \mathrm{E}-03$ \\
\hline $\mathrm{ESCO} 2$ & Establishment of sister chromatid c.N-acetyltransferase 2 & -2.61 & $1.93 \mathrm{E}-06$ & $3.00 \mathrm{E}-03$ \\
\hline GEN1 & GEN1 Holliday junction 5 flap endonuclease & -2.61 & $6.76 \mathrm{E}-05$ & $1.39 \mathrm{E}-02$ \\
\hline SPC25 & SPC25, NDC80 kinetochore complex component & -2.61 & $9.19 \mathrm{E}-06$ & $6.00 \mathrm{E}-03$ \\
\hline TACC3 & Transforming, acidic coiled-coil containing protein 3 & -2.61 & 4.29E-06 & $4.60 \mathrm{E}-03$ \\
\hline DEPDC1 & DEP d.c. 1 & -2.62 & $3.00 \mathrm{E}-04$ & $2.99 \mathrm{E}-02$ \\
\hline HJURP & Holliday junction recognition protein & -2.63 & $3.58 \mathrm{E}-06$ & $4.40 \mathrm{E}-03$ \\
\hline EXO1 & Exonuclease 1 & -2.65 & $1.92 \mathrm{E}-05$ & $7.90 \mathrm{E}-03$ \\
\hline KIF18A & Kinesin fam. mem. 18A & -2.65 & $8.64 \mathrm{E}-05$ & $1.56 \mathrm{E}-02$ \\
\hline KIAA1524 & KIAA1524 & -2.67 & 2.00E-04 & $2.65 \mathrm{E}-02$ \\
\hline LMNB1 & Lamin B1 & -2.67 & 2.37E-05 & $8.60 \mathrm{E}-03$ \\
\hline CDK1 & Cyclin-dependent kinase 1 & -2.68 & $7.24 \mathrm{E}-05$ & $1.42 \mathrm{E}-02$ \\
\hline SERTAD4 & SERTA d.c. 4 & -2.68 & $4.00 \mathrm{E}-04$ & $3.72 \mathrm{E}-02$ \\
\hline MCM10 & MCM 10 replication initiation factor & -2.70 & $1.66 \mathrm{E}-05$ & $7.50 \mathrm{E}-03$ \\
\hline KIF15 & Kinesin fam. mem. 15 & -2.71 & $9.35 \mathrm{E}-06$ & $6.00 \mathrm{E}-03$ \\
\hline KIF20A & Kinesin fam. mem. 20A & -2.73 & $1.81 \mathrm{E}-05$ & $7.80 \mathrm{E}-03$ \\
\hline POLE2 & Polymerase (DNA directed), epsilon 2, accessory su. & -2.75 & $9.01 \mathrm{E}-07$ & $2.30 \mathrm{E}-03$ \\
\hline OIP5 & Opa interacting protein 5 & -2.77 & $2.00 \mathrm{E}-05$ & $8.00 \mathrm{E}-03$ \\
\hline SKA3 & Spindle and kinetochore Associated complex su. 3 & -2.77 & $9.33 \mathrm{E}-06$ & $6.00 \mathrm{E}-03$ \\
\hline CDCA7 & Cell division cycle associated 7 & -2.78 & $6.94 \mathrm{E}-06$ & $5.70 \mathrm{E}-03$ \\
\hline DNA2 & DNA replication Helicase/nuclease 2 & -2.79 & $1.71 \mathrm{E}-05$ & $7.50 \mathrm{E}-03$ \\
\hline NDC80 & NDC80 kinetochore complex component & -2.82 & $1.00 \mathrm{E}-04$ & $1.73 \mathrm{E}-02$ \\
\hline CENPK & Centromere protein $\mathrm{K}$ & -2.83 & $1.48 \mathrm{E}-05$ & $7.40 \mathrm{E}-03$ \\
\hline $\mathrm{CDC7}$ & Cell division cycle 7 & -2.86 & $1.61 \mathrm{E}-06$ & $2.80 \mathrm{E}-03$ \\
\hline ATAD5 & ATPase fam., AAA d.c. 5 & -2.87 & $1.15 \mathrm{E}-05$ & $6.50 \mathrm{E}-03$ \\
\hline FANCM & Fanconi anemia complementation group $\mathrm{M}$ & -2.88 & $1.23 \mathrm{E}-05$ & $6.80 \mathrm{E}-03$ \\
\hline FAM111B & Fam. with sequence similarity 111, mem. B & -2.89 & $1.68 \mathrm{E}-06$ & $2.80 \mathrm{E}-03$ \\
\hline PBK & PDZ binding kinase & -2.89 & 4.74E-05 & $1.22 \mathrm{E}-02$ \\
\hline CCNA2 & Cyclin A2 & -2.91 & $5.24 \mathrm{E}-06$ & $5.10 \mathrm{E}-03$ \\
\hline SGOL1-AS1 & SGOL1 antisense RNA 1 & -2.92 & $1.00 \mathrm{E}-04$ & $1.80 \mathrm{E}-02$ \\
\hline BRCA2 & Breast cancer 2, early onset & -2.94 & $6.66 \mathrm{E}-05$ & $1.37 \mathrm{E}-02$ \\
\hline CDCA2 & Cell division cycle associated 2 & -3.00 & $8.82 \mathrm{E}-06$ & $6.00 \mathrm{E}-03$ \\
\hline PRIM1 & Primase, DNA, polypeptide 1 (49kDa) & -3.01 & $6.46 \mathrm{E}-07$ & $2.10 \mathrm{E}-03$ \\
\hline CDCA8 & Cell division cycle associated 8 & -3.06 & $1.63 \mathrm{E}-06$ & $2.80 \mathrm{E}-03$ \\
\hline GPX8 & Glutathione peroxidase 8 (putative) & -3.17 & $6.00 \mathrm{E}-04$ & 4.93E-02 \\
\hline FAM83D & Fam. with sequence similarity 83 , mem. D & -3.20 & $2.77 \mathrm{E}-06$ & $3.50 \mathrm{E}-03$ \\
\hline POLQ & Polymerase (DNA directed), theta & -3.30 & $1.00 \mathrm{E}-04$ & $1.70 \mathrm{E}-02$ \\
\hline BORA & Bora, aurora kinase A activator & -3.53 & 4.12E-05 & $1.16 \mathrm{E}-02$ \\
\hline DSCC1 & DNA replication and sister chromatid cohesion 1 & -3.60 & $2.02 \mathrm{E}-06$ & $3.00 \mathrm{E}-03$ \\
\hline SGOL1 & Shugoshin-like 1 (S. pombe) & -3.61 & $1.29 \mathrm{E}-05$ & $6.90 \mathrm{E}-03$ \\
\hline MIR924 & MicroRNA 924 & -3.68 & $2.00 \mathrm{E}-04$ & 2.17E-02 \\
\hline
\end{tabular}




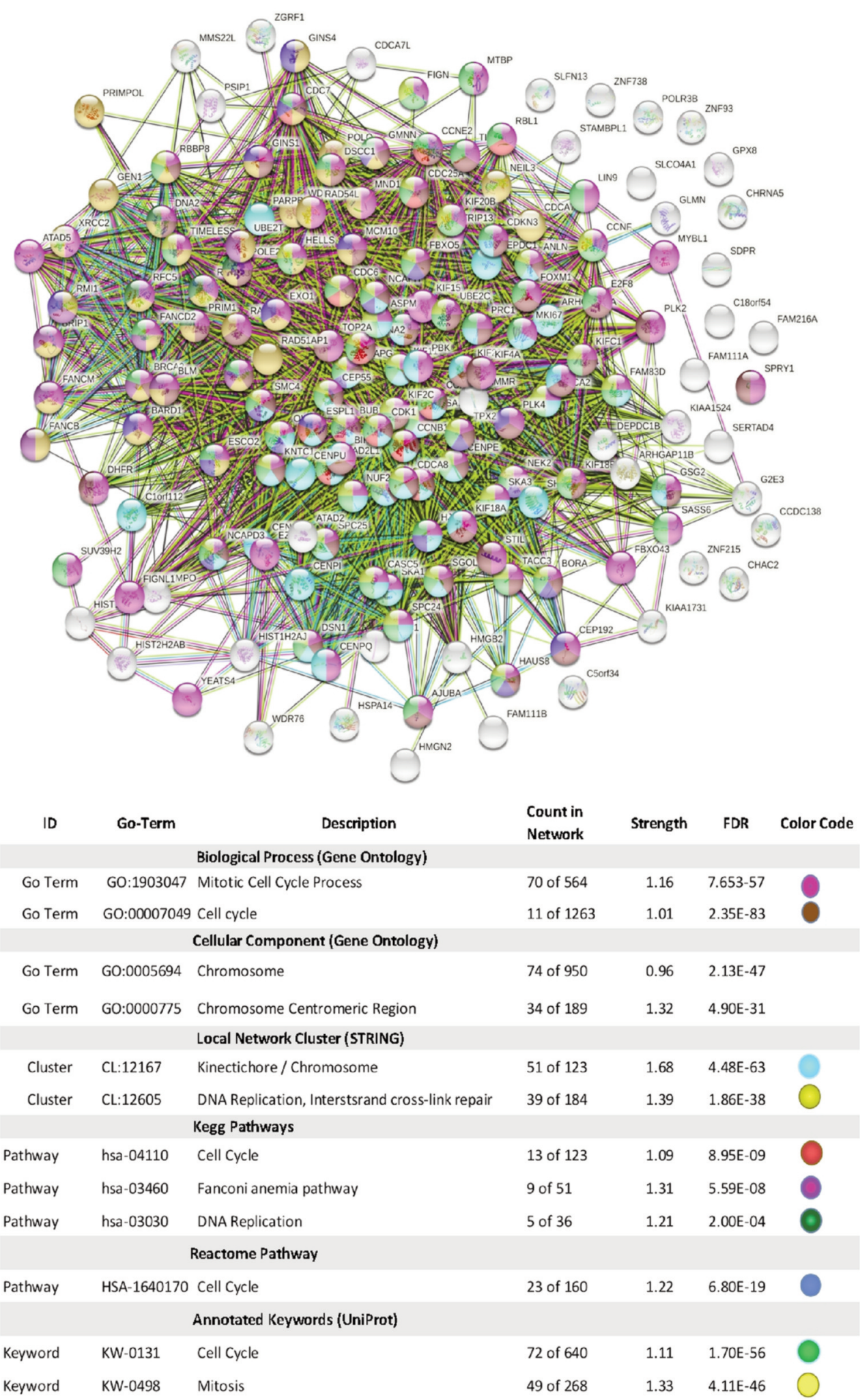

Figure 5. Stringdb relational network analysis of down-regulated DEGS caused by WYE (Low) $15 \mu \mathrm{g} / \mathrm{ml}$ vs. untreated controls after meeting selection criteria; $-2<x>+2$ fold change, $p$-Value $<0.05$ and FDR $p$-Value $<0.05$. The data in the corresponding table: represent database used, ID \#s within a database, description of system altered, count in the network for system, strength of relationship and the false discovery rate (FDR) p-Value. Color codes indicate genes (by symbol) in the string diagram corresponding to the table class description. 


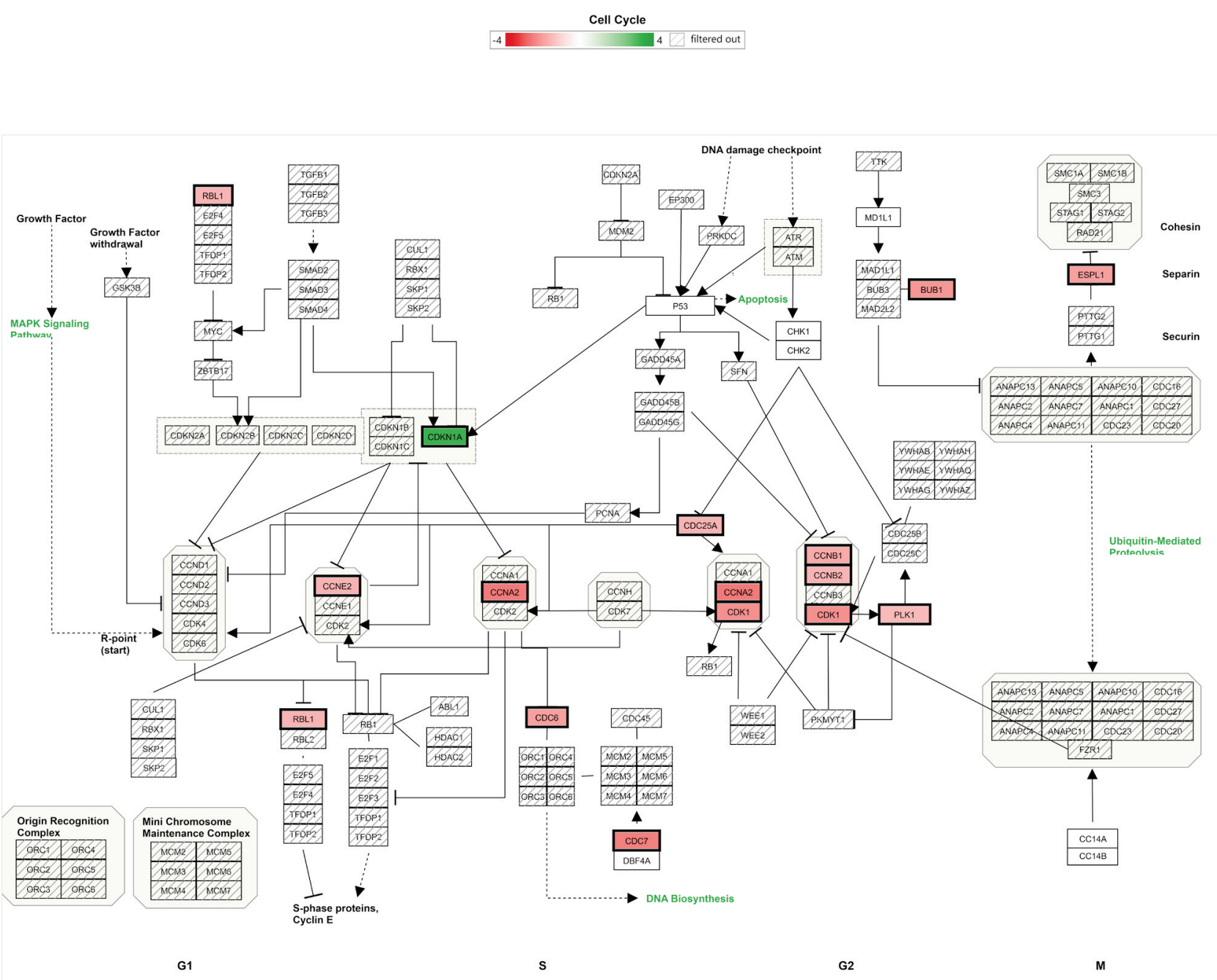

Figure 6. Cell cycle Wikipathway analysis report for DEGS caused by WYE (Low) $15 \mu \mathrm{g} / \mathrm{ml}$ vs. untreated controls after meeting selection criteria; $-2<x>+2, p$-Value $<0.05$ and FDR $p$-Value $<0.05$. DEGS are color coded (red=down), (green=up) with color intensity darker with fold higher fold change. Gene symbol denoted by cross bars /// were not altered.

To our knowledge, this is the first scientific report describing the pro-inflammatory immune-stimulating properties of WYE in a cancer cell line, amongst what appears to be an absence in the literature of similar type studies. Meanwhile, for over 60 years, the research literature has been well established for describing the effects of lowdose saponins as immune-stimulating vaccine adjuvants, which carry out the sole purpose of stimulating a strong, long-lasting learned immune response to administered vaccine antigens. Saponin adjuvants bear a similar molecular similarity to known saponins in WYE, some of which include Quil A, QS-21 from Quillaja, and saponins in the Momordica (35), Glycyrrhiza (36), and the Dioscorea botanical species itself (37). Botanically derived saponin adjuvants boost the immune system by increasing the Th1/Th2 cell-mediated response, antibody production, targeted cytotoxic T-CD4+ cell response with concurrent stimulation of a variety of cytokines [IL-2, IL-10, IL-12 (p70) and IFN- $\gamma]$ (20, 38-44). Yet, interestingly, most of all of the studies on saponin adjuvants have been carried out only in the presence of the antigenic substance containing the vaccine. To add to this gap in the literature, only a few studies have explored the immune-stimulating properties of saponin-rich herbs, which describe an effect on the innate immune response by crude extracts or compounds within Dioscorea species. These changes include capacity to stimulate phagocytosis in macrophages, enhance natural killer (NK) cell activity, activate Toll-like receptor 4 (TLR4) and activate downstream 


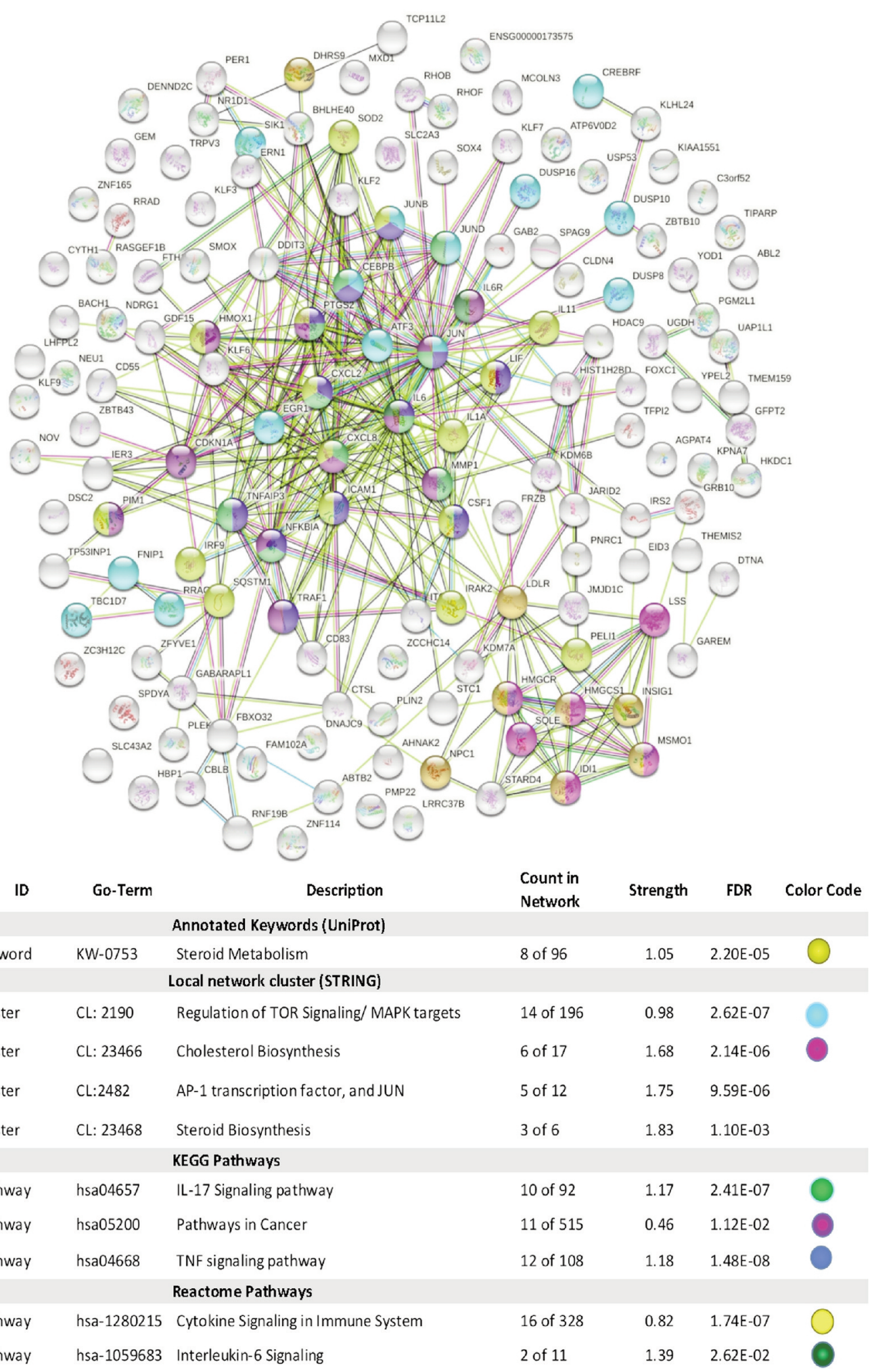

Figure 7. Stringdb relational network analysis of up-regulated DEGS caused by WYE (Low) $15 \mu \mathrm{g} / \mathrm{mL}$ vs. untreated controls after meeting selection criteria; $-2<x>+2$, $p$-Value $<0.05$ and FDR $p$-Value $<0.05$. The data represent database used, ID \#s within a database, description of system altered, count in the network for system, strength of relationship and the false discovery rate (FDR) p-Value. Color codes indicate genes (by symbol) in the string diagram corresponding to the table class description. 


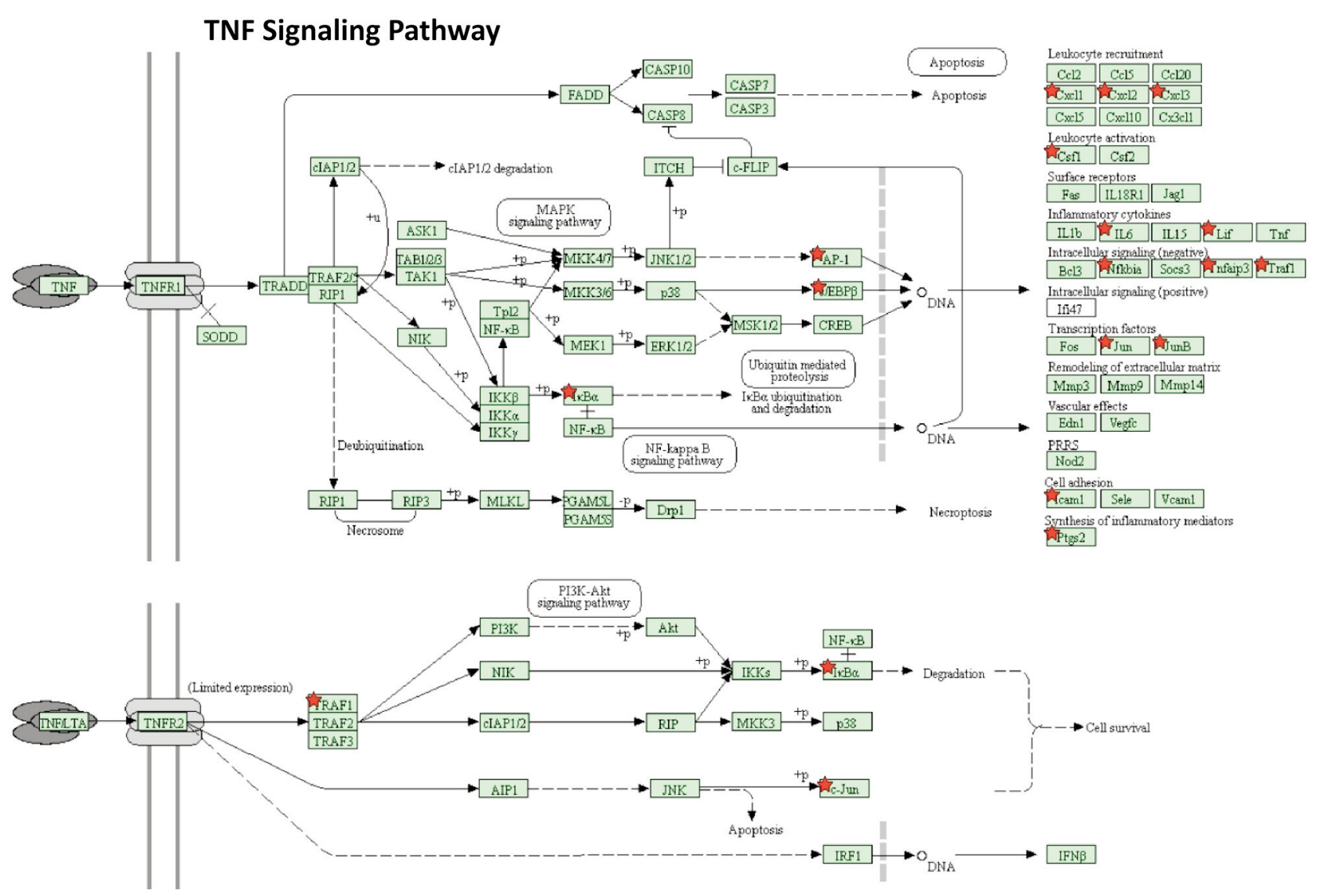

Figure 8. TNF signaling Kegg Pathway report for up-regulated DEGS caused by WYE (Low) $15 \mu \mathrm{g} / \mathrm{ml}$ vs. untreated controls after meeting selection criteria; $-2<x>+2$ fold change, $p$-Value $<0.05$ and FDR p-Value $<0.05$. Up-regulated DEGS are demarcated by a red star.

signaling pathways (ERK/JNK, and p38) involving cytokine release (e.g., IL-2, IFN- $\gamma$, TNF- $\alpha$, IL-1b, and IL-6) (45-47). Similarly, Dioscorea glycoproteins alone can trigger infiltration and recruitment of macrophages, lymphocytes, neutrophils, and monocytes while at the same time augmenting NK cytotoxic cell response $(48,49)$. There is some remote similarity in the manner in which biological responses to the FDA approved saponin adjuvant used for the zoster vaccine (50) AS01 (the QS-21 saponin) works to activate the immune system, such as acting on TLR4 signaling, however, reports central around activation of the adaptive immune response $(38,51-53)$. In turn, there are also studies showing that other types of saponin-rich plants can stimulate both the innate and adaptive immune response by activation of TLR4, NK cells, humoral and cell-mediated immunity, macrophage phagocytosis, cytokine and immunoglobulin production, and $\mathrm{T} \mathrm{CD} 8+$ cell-mediated anticancer immune response, such as the case for Codonopsis pilosula $(54,55)$ and Astragalus (56-58).
While data in this work show WYE to evoke some immune response in the cancer cells itself, the impact of this remains speculative. We cannot exclude the possibility that it could also worsen existing cancers with an inflammatory component. In brief, the immune system is a double-edged sword as it plays a role in both the destruction of/and pathological advancement of cancer. Initiation of cancer can occur from many injurious environmental elements, including; chronic persistent inflammation, exposure to pathogens, irritants, toxins with greater vulnerability occurring in immunocompromised individuals. There is a delicate balance between immunosuppression (under-active) and inflammation (overactive) which controls the initial susceptibility to cancer and various infections.

A healthy immune system will recognize and destroy malignant cells on demand. In established cancers, the host immune system no longer recognizes malignant cells (immune escape) but instead supports the survival, 
A

B

\begin{tabular}{|c|c|c|c|c|}
\hline \multicolumn{5}{|c|}{ mRNA Microarray Values (Control vs. WYE Low) } \\
\hline Gene & & & & \\
\hline Symbol & Description & Fold Change & $p$-Value & FDR $p$-Value \\
\hline CSF2 & $\begin{array}{c}\text { colony } \\
\text { stimulating } \\
\text { factor } 2 \\
\text { (granulocyte- } \\
\text { macrophage) }\end{array}$ & 1.57 & 0.005 & $1.67 \mathrm{E}-01$ \\
\hline IL15 & interleukin 15 & 1.26 & 0.017 & $3.08 \mathrm{E}-01$ \\
\hline IL6 & interleukin 6 & 2.23 & $<0.001$ & $2.16 \mathrm{E}-02$ \\
\hline TIMP2; & TIMP & 1.52 & 0.002 & $9.41 \mathrm{E}-02$ \\
\hline CEP295N & metallopeptida & & & \\
\hline L & $\begin{array}{l}\text { se inhibitor 2; } \\
\text { CEP295 N- } \\
\text { terminal like }\end{array}$ & & & \\
\hline IL6R & $\begin{array}{c}\text { interleukin } 6 \\
\text { receptor }\end{array}$ & 2.39 & $<0.001$ & 1.81E-02 \\
\hline CXCL8 & $\begin{array}{c}\text { chemokine (C- } \\
\mathrm{X}-\mathrm{C} \text { motif) } \\
\text { ligand } 8\end{array}$ & 9.09 & $<0.001$ & 1.83E-05 \\
\hline
\end{tabular}

Figure 9. Supernatant cytokine detection vs. mRNA transcript. Cytokine released in untreated controls $v s$. (WYE-Low, $15 \mu \mathrm{g} / \mathrm{ml}$ ) in supernatants obtained from the same pellets used for microarray analysis and analyzed by a human cytokine array. The data represents matched changes occurring in both the protein antibody with *p-Values $<0.05$ in both sets, where array values were set at selection criteria; any fold change, $p$-Value $<0.05$ and no filter on FDR $p$-Values $(B)$. There was a high degree of matching values between proteins released in the supernatant and the $m R N A$ produced for those proteins.

proliferation, and metastasis of cancer. This is carried out by the formation of a protective inflammatory barrier within the tumor microenvironment (TME) $(59,60)$ which fosters cancer growth while at the same time suppresses the body's immune system to recognize and target cancer (61). The elevation of cytokines released by the tumor tissue itself could worsen pre-existing cancers, driving inward trafficking of leukocyte subpopulations such as monocytes toward the tumor (62), which along with acidity, can polarize and mature into M2- tumor-associated macrophages (TAMS) $(63,64)$. The M2 tumor-promoting phenotype is largely immunosuppressive, aligning with the increased presence of cytokines (IL-6, IL-8, IL-10), COX2, cathepsins, IL-1A, and MMPS within the TME,

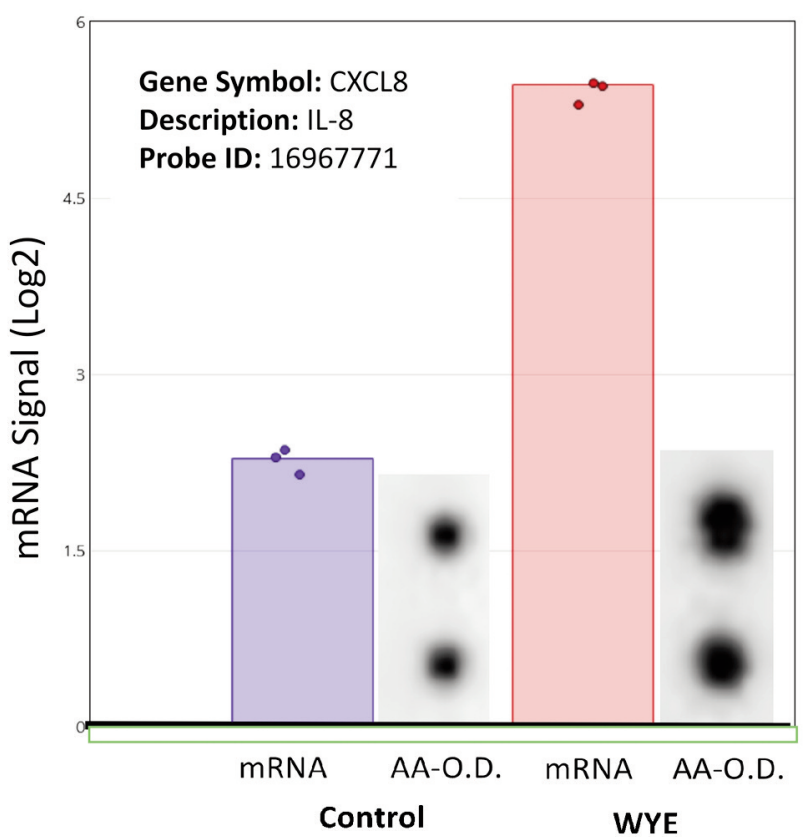

Figure 10. Supernatant cytokine detection. Supernatants collected from pellets used for microarray analysis (WYE-Low, 15ug/ml) show semiquantitative changes in IL-8 by anti-body array (densitometry spot duplicates), demarcated alongside transcriptomic microarray chip spot probe arrays for IL-8 in MDA-MB-231 cells.

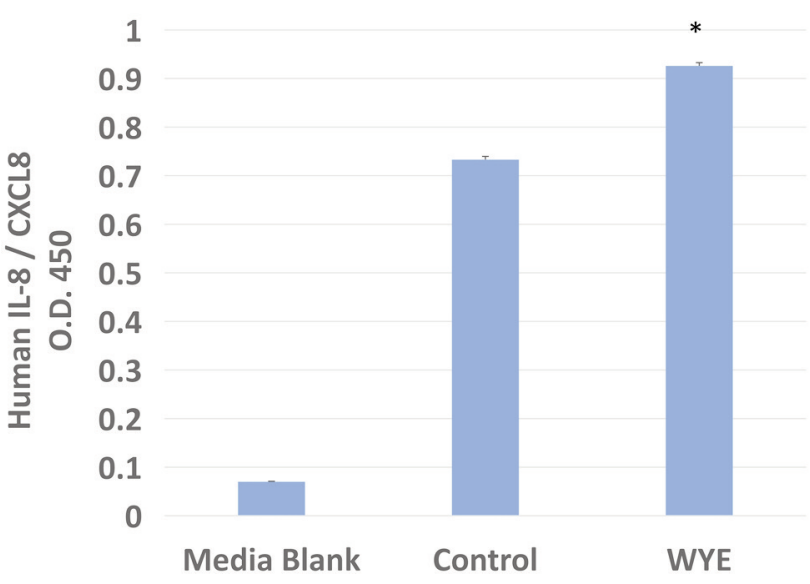

Figure 11. Supernatants collected from pellets used for microarray analysis (WYE-Low, $15 \mu \mathrm{g} / \mathrm{ml}$ ) show quantitative changes in $I L-8$ as determined by ELISA. The data represent the mean \pm S.E.M for optical densitometry values, $n=3$ and significant differences between the control and treatment was determined by a students $t$-test; $* p<0.05$.

creating a highly inflammatory aggressive breast cancer with poor clinical outcome (65-72). In the current work, we showed that WYE at very low concentrations, in theory, could perpetuate the M2 phenotype by establishing 
tumor cell production of $\mathrm{COX} 2$, and the release of cathepsins, MMP1, IL-8, IL-6, IL-1A, and CCL2, the consequences of which would be counter-indicated and harmful for cancer patients.

While on the one hand, the WYE used in this study provokes a rise in aggravating tumor cytokines, paradoxically compounds in the Dioscorea species are known to augment the body's natural capacity to target and destroy tumor cells, as described above. The ability to redirect the body to destroy its own tumor cells is the aim of current-day research in developing immune-modulating anticancer drugs. These therapies aim to restore the body's natural immune killing capacity by a) penetrating through the TME and $b$ ) activating tumor recognition and destruction by the body's tumor CD8+ T cytotoxic and NK. Cells, both being used in adoptive immune therapies (AIT) $(73,74)$. While there are most certainly natural compounds unidentified to date that can do this, at the current time, AITs involves using the patient's blood to derive peripheral blood mononuclear cells (PBMCs), which are genetically engineered or modified then reinfused back into the same patient to target cancer $(59,75)$. However, it would suffice to say that any agent, drug, or process can mimic the effect of AITs to boost the body's own NK cells (76) cytotoxic T $(\mathrm{CD} 8+) / \mathrm{Th}(\mathrm{CD} 4+)$, antigen-presenting dendritic cells (DCs)/cytokine-induced killer (CIK) cells (DC-CIK cells therapies) (77-79) would, in theory, establish long term immunity and positive patient outcome including for individuals with stage IV breast and TNBC cancers (80-83).

In conclusion, this work provides an overall transcriptomic analysis of WYE at sub-lethal concentrations, corroborating existing evidence by demonstrating its cytostatic effects and establishing a unique immunestimulatory response. This work emphasizes the need for future research to investigate the immune stimulatory effects of saponin-rich herbs as it relates to cancer prevention and/ or treatment.

\section{Availability of Data and Material}

The dataset has been deposited to NIH. Gene Expression Omnibus located at: https://www.ncbi.nlm.nih.gov/geo/query/acc.cgi?acc= GSE180621.

\section{Conflicts of Interest}

The Authors declare that they have no conflicts of interest.

\section{Authors' Contributions}

EM and AA conducted studies on cell viability, saponins, antibody arrays, ELISA, and microarray. SDR and KS were involved with troubleshooting, literature review, manuscript preparation, and KS oversaw and guided this project.

\section{Acknowledgements}

This research was supported by the National Institute of Minority Health and Health Disparities of the National Institutes of Health through Grant Number U54 MD 007582 and Grant Number P20 MD 006738

\section{References}

1 Park MK, Kwon HY, Ahn WS, Bae S, Rhyu MR and Lee Y: Estrogen activities and the cellular effects of natural progesterone from wild yam extract in mcf-7 human breast cancer cells. Am J Chin Med 37(1): 159-167, 2009. PMID: 19222119. DOI: 10.1142/S0192415X09006746

2 Aumsuwan P, Khan SI, Khan IA, Avula B, Walker LA, Helferich WG, Katzenellenbogen BS and Dasmahapatra AK: Evaluation of wild yam (Dioscorea villosa) root extract as a potential epigenetic agent in breast cancer cells. In Vitro Cell Dev Biol Anim 51(1): 59-71, 2015. PMID: 25148825. DOI: 10.1007/s11626-014-9807-5

3 Depypere HT and Comhaire FH: Herbal preparations for the menopause: beyond isoflavones and black cohosh. Maturitas 77(2): 191-194, 2014. PMID: 24314619. DOI: 10.1016/j.maturitas. 2013.11.001

4 Mazzio E, Badisa R, Mack N, Deiab S and Soliman KF: High throughput screening of natural products for anti-mitotic effects in MDA-MB-231 human breast carcinoma cells. Phytother Res 28(6): 856-867, 2014. PMID: 24105850. DOI: $10.1002 /$ ptr.5065

5 Chiang CT, Way TD, Tsai SJ and Lin JK: Diosgenin, a naturally occurring steroid, suppresses fatty acid synthase expression in HER2-overexpressing breast cancer cells through modulating Akt, mTOR and JNK phosphorylation. FEBS Lett 581(30): 5735-5742, 2007. PMID: 18022396. DOI: 10.1016/j.febslet.2007.11.021

6 Salehi B, Sener B, Kilic M, Sharifi-Rad J, Naz R, Yousaf Z, Mudau FN, Fokou PVT, Ezzat SM, El Bishbishy MH, Taheri Y, Lucariello G, Durazzo A, Lucarini M, Suleria HAR and Santini A: Dioscorea plants: A genus rich in vital nutra-pharmaceuticalsa review. Iran J Pharm Res 18(Suppl1): 68-89, 2019. PMID: 32802090. DOI: 10.22037/ijpr.2019.112501.13795

7 He Z, Chen H, Li G, Zhu H, Gao Y, Zhang L and Sun J: Diosgenin inhibits the migration of human breast cancer MDAMB-231 cells by suppressing Vav2 activity. Phytomedicine 21(6): 871-876, 2014. PMID: 24656238. DOI: 10.1016/j. phymed.2014.02.002

8 Bhuvanalakshmi G, Basappa, Rangappa KS, Dharmarajan A, Sethi G, Kumar AP and Warrier S: Breast cancer stem-like cells are inhibited by diosgenin, a steroidal saponin, by the attenuation of the Wnt $\beta$-catenin signaling via the Wnt antagonist secreted frizzled related protein-4. Front Pharmacol 8: 124, 2017. PMID: 28373842. DOI: 10.3389/fphar.2017.00124

9 Zhao J, Xu Y, Wang C, Ding Y, Chen M, Wang Y, Peng J, Li L and Lv L: Soluplus/TPGS mixed micelles for dioscin delivery in cancer therapy. Drug Dev Ind Pharm 43(7): 1197-1204, 2017. PMID: 28300426. DOI: 10.1080/03639045.2017.1304956

10 Liao WL, Lin JY, Shieh JC, Yeh HF, Hsieh YH, Cheng YC, Lee $\mathrm{HJ}$, Shen $\mathrm{CY}$ and Cheng $\mathrm{CW}$ : Induction of $\mathrm{G} 2 / \mathrm{M}$ phase arrest by diosgenin via activation of Chk1 kinase and Cdc25C regulatory pathways to promote apoptosis in human breast cancer cells. Int J Mol Sci 21(1): 172, 2019. PMID: 31881805. DOI: $10.3390 / \mathrm{ijms} 21010172$ 
11 Masood-Ur-Rahman, Mohammad Y, Fazili KM, Bhat KA and Ara T: Synthesis and biological evaluation of novel 3-O-tethered triazoles of diosgenin as potent antiproliferative agents. Steroids 118: 1-8, 2017. PMID: 27864018. DOI: 10.1016/j.steroids.2016. 11.003

12 Yeager JF: Hemolysis by saponin and sodium taurocholate, with special reference to the series of Ryvosh. J Gen Physiol 11(6): 779-787, 1928. PMID: 19872434. DOI: 10.1085/jgp.11.6.779

13 Efimova SS and Ostroumova OS: Is the membrane lipid matrix a key target for action of pharmacologically active plant saponins? Int J Mol Sci 22(6): 3167, 2021. PMID: 33804648 DOI: $10.3390 / \mathrm{ijms} 22063167$

14 Orczyk M, Wojciechowski K and Brezesinski G: The influence of steroidal and triterpenoid saponins on monolayer models of the outer leaflets of human erythrocytes, E. coli and S. cerevisiae cell membranes. J Colloid Interface Sci 563: 207-217, 2020 PMID: 31874308. DOI: 10.1016/j.jcis.2019.12.014

15 Malabed R, Hanashima S, Murata M and Sakurai K: Interactions of OSW-1 with lipid bilayers in comparison with digitonin and soyasaponin. Langmuir 36(13): 3600-3610, 2020. PMID: 32160747. DOI: 10.1021 /acs.langmuir.9b03957

16 Verstraeten SL, Albert M, Paquot A, Muccioli GG, Tyteca D and Mingeot-Leclercq MP: Membrane cholesterol delays cellular apoptosis induced by ginsenoside $\mathrm{Rh} 2$, a steroid saponin. Toxicol Appl Pharmacol 352: 59-67, 2018. PMID: 29782965. DOI: 10.1016/j.taap.2018.05.014

17 Chen M, Balhara V, Jaimes Castillo AM, Balsevich J and Johnston LJ: Interaction of saponin 1688 with phase separated lipid bilayers. Biochim Biophys Acta Biomembr 1859(7): 1263-1272, 2017. PMID: 28389202. DOI: 10.1016/j.bbamem.2017.03.024

$18 \mathrm{Xu}$ XH, Li T, Fong CM, Chen X, Chen XJ, Wang YT, Huang MQ and Lu JJ: Saponins from Chinese medicines as anticancer agents. Molecules 21(10): 1326, 2016. PMID: 27782048. DOI: 10.3390/molecules21101326

19 Sudji IR, Subburaj Y, Frenkel N, García-Sáez AJ and Wink M: Membrane disintegration caused by the steroid saponin digitonin is related to the presence of cholesterol. Molecules 20(11): 2014620160, 2015. PMID: 26569199. DOI: 10.3390/molecules201119682

20 Lacaille-Dubois MA and Wagner H: A review of the biological and pharmacological activities of saponins. Phytomedicine 2(4): 363-386, 1996. PMID: 23194774. DOI: 10.1016/S09447113(96)80081-X

21 Koczurkiewicz P, Klaś K, Grabowska K, Piska K, Rogowska K, Wójcik-Pszczoła K, Podolak I, Galanty A, Michalik M and Pękala E: Saponins as chemosensitizing substances that improve effectiveness and selectivity of anticancer drug-Minireview of in vitro studies. Phytother Res 33(9): 2141-2151, 2019. PMID: 31294509. DOI: $10.1002 /$ ptr.6371

22 Tong QY, He Y, Zhao QB, Qing Y, Huang W and Wu XH: Cytotoxicity and apoptosis-inducing effect of steroidal saponins from Dioscorea zingiberensis Wright against cancer cells. Steroids 77(12): 1219-1227, 2012. PMID: 22575181. DOI: 10.1016/j.steroids.2012.04.019

23 Jaiaree N, Itharat A and Kumapava K: Cytotoxic saponin against lung cancer cells from Dioscorea birmanica Prain \& Burkill. J Med Assoc Thai 93(Suppl 7): S192-S197, 2010. PMID: 21294414

24 Schneider CA, Rasband WS and Eliceiri KW: NIH Image to ImageJ: 25 years of image analysis. Nat Methods 9(7): 671-675, 2012. PMID: 22930834. DOI: $10.1038 /$ nmeth 2089
25 Jones KH and Senft JA: An improved method to determine cell viability by simultaneous staining with fluorescein diacetatepropidium iodide. J Histochem Cytochem 33(1): 77-79, 1985. PMID: 2578146. DOI: 10.1177/33.1.2578146

26 Crowley LC, Christensen ME and Waterhouse NJ: Measuring mitochondrial transmembrane potential by TMRE staining. Cold Spring Harb Protoc 2016(12), 2016. PMID: 27934682. DOI: 10.1101/pdb.prot087361

27 McMillian MK, Li L, Parker JB, Patel L, Zhong Z, Gunnett JW, Powers WJ and Johnson MD: An improved resazurin-based cytotoxicity assay for hepatic cells. Cell Biol Toxicol 18(3): 157173, 2002. PMID: 12083422. DOI: 10.1023/a:1015559603643

28 Szklarczyk D, Franceschini A, Kuhn M, Simonovic M, Roth A, Minguez P, Doerks T, Stark M, Muller J, Bork P, Jensen LJ and von Mering C: The STRING database in 2011: functional interaction networks of proteins, globally integrated and scored. Nucleic Acids Res 39(Database issue): D561-D568, 2011. PMID: 21045058. DOI: 10.1093/nar/gkq973

29 Szklarczyk D, Gable AL, Nastou KC, Lyon D, Kirsch R, Pyysalo S, Doncheva NT, Legeay M, Fang T, Bork P, Jensen LJ and von Mering C: The STRING database in 2021: customizable proteinprotein networks, and functional characterization of user-uploaded gene/measurement sets. Nucleic Acids Res 49(D1): D605-D612, 2021. PMID: 33237311. DOI: 10.1093/nar/gkaa1074

30 Huang DW, Sherman BT, Tan Q, Collins JR, Alvord WG, Roayaei J, Stephens R, Baseler MW, Lane HC and Lempicki RA: The DAVID Gene Functional Classification Tool: a novel biological module-centric algorithm to functionally analyze large gene lists. Genome Biol 8(9): R183, 2007. PMID: 17784955. DOI: $10.1186 / \mathrm{gb}-2007-8-9-\mathrm{r} 183$

31 Duangprompo W, Aree K, Itharat A and Hansakul P: Effects of 5,6-dihydroxy-2,4-dimethoxy-9,10-dihydrophenanthrene on $\mathrm{G}_{2} / \mathrm{M}$ cell cycle arrest and apoptosis in human lung carcinoma cells. Am J Chin Med 44(7): 1473-1490, 2016. PMID: 27776429. DOI: $10.1142 / \mathrm{S} 0192415 X 16500828$

32 Xie YL, Fan M, Jiang RM, Wang ZL and Li Y: Deltonin induced both apoptosis and autophagy in head and neck squamous carcinoma FaDu cell. Neoplasma 62(3): 419-431, 2015. PMID: 25866222. DOI: 10.4149/neo_2015_050

33 Wang G, Chen H, Huang M, Wang N, Zhang J, Zhang Y, Bai G, Fong WF, Yang $M$ and Yao $X$ : Methyl protodioscin induces G2/M cell cycle arrest and apoptosis in HepG2 liver cancer cells. Cancer Lett 241(1): 102-109, 2006. PMID: 16458429. DOI: 10.1016/j.canlet.2005.10.050

34 Li X, Qu Z, Jing S, Li X, Zhao C, Man S, Wang Y and Gao W: Dioscin-6'-O-acetate inhibits lung cancer cell proliferation via inducing cell cycle arrest and caspase-dependent apoptosis. Phytomedicine 53: 124-133, 2019. PMID: 30668391. DOI: 10.1016/j.phymed.2018.09.033

35 Wang P, Ding X, Kim H, Michalek SM and Zhang P: Structural effect on adjuvanticity of saponins. J Med Chem 63(6): 3290-3297, 2020. PMID: 32101001. DOI: 10.1021/acs.jmedchem.9b02063

36 Alexyuk PG, Bogoyavlenskiy AP, Alexyuk MS, Turmagambetova AS, Zaitseva IA, Omirtaeva ES and Berezin VE: Adjuvant activity of multimolecular complexes based on Glycyrrhiza glabra saponins, lipids, and influenza virus glycoproteins. Arch Virol 164(7): 1793-1803, 2019. PMID: 31079211. DOI: 10.1007/s00705-019-04273-2

37 Wei WC, Wang JH, Aravindaram K, Wang SJ, Hsu CC, Li CJ, Wen CC, Sheu JH and Yang NS: Polysaccharides from dioscorea 
(shān yào) and other phytochemicals enhance antitumor effects induced by DNA vaccine against melanoma. J Tradit Complement Med 4(1): 42-48, 2014. PMID: 24872932. DOI: $10.4103 / 2225-4110.124342$

38 Wang P: Natural and synthetic saponins as vaccine adjuvants. Vaccines (Basel) 9(3): 222, 2021. PMID: 33807582. DOI: 10.3390/vaccines 9030222

39 Tian JH, Patel N, Haupt R, Zhou H, Weston S, Hammond H, Logue J, Portnoff AD, Norton J, Guebre-Xabier M, Zhou B, Jacobson K, Maciejewski S, Khatoon R, Wisniewska M, Moffitt W, Kluepfel-Stahl S, Ekechukwu B, Papin J, Boddapati S, Jason Wong C, Piedra PA, Frieman MB, Massare MJ, Fries L, Bengtsson KL, Stertman L, Ellingsworth L, Glenn G and Smith G: SARS-CoV-2 spike glycoprotein vaccine candidate NVXCoV2373 immunogenicity in baboons and protection in mice. Nat Commun 12(1): 372, 2021. PMID: 33446655. DOI: 10.1038/s41467-020-20653-8

40 Richou R, Jensen R and Belin C: [Research on saponin, an adjuvant substance which stimulates immunity. I]. Rev Immunol Ther Antimicrob 28: 49-62, 1964. PMID: 14187805.

41 Kensil CR: Saponins as vaccine adjuvants. Crit Rev Ther Drug Carrier Syst 13(1-2): 1-55, 1996. PMID: 8853958.

42 Wang P, Škalamera Đ, Sui X, Zhang P and Michalek SM: Synthesis and evaluation of QS-7-based vaccine adjuvants. ACS Infect Dis 5(6): 974-981, 2019. PMID: 30920199. DOI: 10.1021/acsinfecdis.9b00039

43 Aguado-Martínez A, Basto AP, Müller J, Balmer V, Manser V, Leitão A and Hemphill A: N-terminal fusion of a toll-like receptor 2-ligand to a Neospora caninum chimeric antigen efficiently modifies the properties of the specific immune response. Parasitology 143(5): 606-616, 2016. PMID: 26932317. DOI: $10.1017 / \mathrm{S} 0031182016000056$

44 Morein B, Hu KF and Abusugra I: Current status and potential application of ISCOMs in veterinary medicine. Adv Drug Deliv Rev 56(10): 1367-1382, 2004. PMID: 15191787. DOI: 10.1016/j.addr.2004.02.004

45 Hao Hao LX and Zhao XH: Report - In vitro immune potentials of a water-soluble polysaccharide extract from Dioscorea opposita planted in Henan Province, China. Pak J Pharm Sci 30(4): 1383-1388, 2017. PMID: 29039342.

46 Lee BH, Hsu WH, Liao TH and Pan TM: Inhibition of leukemia proliferation by a novel polysaccharide identified from Monascus-fermented dioscorea via inducing differentiation. Food Funct 3(7): 758-764, 2012. PMID: 22584829. DOI: $10.1039 / \mathrm{c} 2 \mathrm{fo} 30026 \mathrm{e}$

47 Panthong S, Ruangnoo S, Thongdeeying P, Sriwanthana B and Itharat A: Immunomodulatory activity of Dioscorea membranacea Pierre rhizomes and of its main active constituent Dioscorealide B. BMC Complement Altern Med 14: 403, 2014. PMID: 25318548. DOI: 10.1186/1472-6882-14-403

48 Huong PT and Jeon YJ: Macrophage activation by glycoprotein isolated from Dioscorea batatas. Toxicol Res 27(3): 167-172, 2011. PMID: 24278568. DOI: 10.5487/TR.2011.27.3.167

49 Huong PT, Lee CH, Li MH, Lee MY, Kim JK, Lee SM, Seon $\mathrm{JH}$, Lee DC and Jeon YJ: Characterization and immunopotentiating effects of the glycoprotein isolated from dioscorea batatas. Korean J Physiol Pharmacol 15(2): 101-106, 2011. PMID: 21660150. DOI: 10.4196/kjpp.2011.15.2.101

50 Giordano G, Segal L, Prinsen M, Wijnands MV, Garçon N and Destexhe E: Non-clinical safety assessment of single and repeated administration of gE/AS01 zoster vaccine in rabbits. $\mathrm{J}$ Appl Toxicol 37(2): 132-141, 2017. PMID: 27172098. DOI: $10.1002 /$ jat.3329

51 Shi S, Zhu H, Xia X, Liang Z, Ma X and Sun B: Vaccine adjuvants: Understanding the structure and mechanism of adjuvanticity. Vaccine 37(24): 3167-3178, 2019. PMID: 31047671. DOI: $10.1016 /$ j.vaccine.2019.04.055

52 Fochesato $\mathrm{M}$, Dendouga $\mathrm{N}$ and Boxus $\mathrm{M}$ : Comparative preclinical evaluation of AS01 versus other Adjuvant Systems in a candidate herpes zoster glycoprotein E subunit vaccine. Hum Vaccin Immunother 12(8): 2092-2095, 2016. PMID: 26933767. DOI: $10.1080 / 21645515.2016 .1154247$

53 Sharma R, Palanisamy A, Dhama K, Mal G, Singh B and Singh KP: Exploring the possible use of saponin adjuvants in COVID19 vaccine. Hum Vaccin Immunother 16(12): 2944-2953, 2020. PMID: 33295829. DOI: 10.1080/21645515.2020.1833579

54 He LX, Zhang ZF, Sun B, Chen QH, Liu R, Ren JW, Wang JB and Li Y: Sea cucumber (Codonopsis pilosula) oligopeptides: immunomodulatory effects based on stimulating Th cells, cytokine secretion and antibody production. Food Funct 7(2): 1208-1216, 2016. PMID: 26838796. DOI: 10.1039/c5fo01480h

55 Peng Y, Song Y, Wang Q, Hu Y, He Y, Ren D, Wu L, Liu S, Cong $\mathrm{H}$ and $\mathrm{Zhou} \mathrm{H}$ : In vitro and in vivo immunomodulatory effects of fucoidan compound agents. Int J Biol Macromol 127: 48-56, 2019. PMID: 30593813. DOI: 10.1016/j.ijbiomac. 2018.12.197

56 Wang J, Tong X, Li P, Liu M, Peng W, Cao H and Su W: Bioactive components on immuno-enhancement effects in the traditional Chinese medicine Shenqi Fuzheng Injection based on relevance analysis between chemical HPLC fingerprints and in vivo biological effects. J Ethnopharmacol 155(1): 405-415, 2014. PMID: 24950446. DOI: 10.1016/j.jep.2014.05.038

57 Bamodu OA, Kuo KT, Wang CH, Huang WC, Wu ATH, Tsai JT, Lee KY, Yeh CT and Wang LS: Astragalus polysaccharides (PG2) enhances the M1 polarization of macrophages, functional maturation of dendritic cells, and $\mathrm{T}$ cell-mediated anticancer immune responses in patients with lung cancer. Nutrients 11(10): 2264, 2019. PMID: 31547048. DOI: 10.3390/nu11102264

58 Tian Y, Li X, Li H, Lu Q, Sun G and Chen H: Astragalus mongholicus regulate the Toll-like-receptor 4 meditated signal transduction of dendritic cells to restrain stomach cancer cells. Afr J Tradit Complement Altern Med 11(3): 92-96, 2014. PMID: 25371568. DOI: 10.4314/ajtcam.v11i3.13

59 Salemme V, Centonze G, Cavallo F, Defilippi P and Conti L: The crosstalk between tumor cells and the immune microenvironment in breast cancer: Implications for immunotherapy. Front Oncol 11: 610303, 2021. PMID: 33777750. DOI: $10.3389 /$ fonc .2021 .610303

60 Steven A and Seliger B: The role of immune escape and immune cell infiltration in breast cancer. Breast Care (Basel) 13(1): 1621, 2018. PMID: 29950962. DOI: 10.1159/000486585

61 Gross S and Walden P: Immunosuppressive mechanisms in human tumors: why we still cannot cure cancer. Immunol Lett 116(1): 7-14, 2008. PMID: 18164076. DOI: 10.1016/j.imlet. 2007.11.012

62 Li X, Yao W, Yuan Y, Chen P, Li B, Li J, Chu R, Song H, Xie $\mathrm{D}$, Jiang $\mathrm{X}$ and Wang $\mathrm{H}$ : Targeting of tumour-infiltrating macrophages via CCL2/CCR2 signalling as a therapeutic strategy against hepatocellular carcinoma. Gut 66(1): 157-167, 2017. PMID: 26452628. DOI: 10.1136/gutjnl-2015-310514 
63 Heiskala M, Leidenius M, Joensuu K and Heikkilä P: High expression of CCL2 in tumor cells and abundant infiltration with CD14 positive macrophages predict early relapse in breast cancer. Virchows Arch 474(1): 3-12, 2019. PMID: 30368555 DOI: $10.1007 / \mathrm{s} 00428-018-2461-7$

64 Ohashi T, Inoue $\mathrm{N}$ and Aoki M: The Warburg Effect and M2 Macrophage Polarization in Head and Neck Cancer. Gan To Kagaku Ryoho 47(1): 6-10, 2020. PMID: 32381853.

65 Vendramini-Costa DB and Carvalho JE: Molecular link mechanisms between inflammation and cancer. Curr Pharm Des 18(26): 3831-3852, 2012. PMID: 22632748. DOI: $10.2174 / 138$ 161212802083707

66 Mohamed MM, El-Ghonaimy EA, Nouh MA, Schneider RJ, Sloane BF and El-Shinawi M: Cytokines secreted by macrophages isolated from tumor microenvironment of inflammatory breast cancer patients possess chemotactic properties. Int J Biochem Cell Biol 46: 138-147, 2014. PMID: 24291763. DOI: 10.1016/j.biocel.2013.11.015

67 Sousa S, Brion R, Lintunen M, Kronqvist P, Sandholm J, Mönkkönen J, Kellokumpu-Lehtinen PL, Lauttia S, Tynninen O, Joensuu H, Heymann D and Määttä JA: Human breast cancer cells educate macrophages toward the M2 activation status. Breast Cancer Res 17: 101, 2015. PMID: 26243145. DOI: 10.1186/s13058-015-0621-0

68 Myers KV, Pienta KJ and Amend SR: Cancer cells and M2 macrophages: Cooperative invasive ecosystem engineers. Cancer Control 27(1): 1073274820911058, 2020. PMID: 32129079. DOI: $10.1177 / 1073274820911058$

69 Yang M, Liu J, Shao J, Qin Y, Ji Q, Zhang X and Du J: Cathepsin S-mediated autophagic flux in tumor-associated macrophages accelerate tumor development by promoting M2 polarization. Mol Cancer 13: 43, 2014. PMID: 24580730. DOI: 10.1186/1476-4598-13-43

70 Xu J, Yu Y, He X, Niu N, Li X, Zhang R, Hu J, Ma J, Yu X, Sun $\mathrm{Y}, \mathrm{Ni} \mathrm{H}$ and Wang F: Tumor-associated macrophages induce invasion and poor prognosis in human gastric cancer in a cyclooxygenase-2/MMP9-dependent manner. Am J Transl Res 11(9): 6040-6054, 2019. PMID: 31632572.

71 Vinnakota K, Zhang Y, Selvanesan BC, Topi G, Salim T, SandDejmek J, Jönsson G and Sjölander A: M2-like macrophages induce colon cancer cell invasion via matrix metalloproteinases. J Cell Physiol 232(12): 3468-3480, 2017. PMID: 28098359. DOI: $10.1002 /$ jcp. 25808

72 You D, Jeong Y, Yoon SY, Kim SA, Lo E, Kim SW, Lee JE, Nam SJ and Kim S: Entelon ${ }^{\circledR}$ (Vitis vinifera seed extract) prevents cancer metastasis via the downregulation of Interleukin-1 alpha in triple-negative breast cancer cells. Molecules 26(12): 3644, 2021. PMID: 34203721. DOI: 10.3390/molecules26123644

73 Seliger B and Massa C: Immune therapy resistance and immune escape of tumors. Cancers (Basel) 13(3): 551, 2021. PMID: 33535559. DOI: $10.3390 /$ cancers 13030551

74 Sanchez CE, Dowlati EP, Geiger AE, Chaudhry K, Tovar MA, Bollard CM and Cruz CRY: NK cell adoptive immunotherapy of cancer: Evaluating recognition strategies and overcoming limitations. Transplant Cell Ther 27(1): 21-35, 2021. PMID: 33007496. DOI: 10.1016/j.bbmt.2020.09.030
75 Tonn T, Becker S, Esser R, Schwabe D and Seifried E: Cellular immunotherapy of malignancies using the clonal natural killer cell line NK-92. J Hematother Stem Cell Res 10(4): 535-544, 2001. PMID: 11522236. DOI: 10.1089/15258160152509145

76 Biswas BK, Guru SA, Sumi MP, Jamatia E, Gupta RK, Lali P, Konar BC, Saxena A and Mir R: Natural killer cells expanded and preactivated exhibit enhanced antitumor activity against different tumor cells in vitro. Asian Pac J Cancer Prev 21(6): 1595-1605, 2020. PMID: 32592353. DOI: 10.31557/APJCP. 2020.21.6.1595

77 Abbott RC, Cross RS and Jenkins MR: Finding the keys to the CAR: Identifying novel target antigens for $\mathrm{T}$ cell redirection immunotherapies. Int J Mol Sci 21(2): 515, 2020. PMID: 31947597. DOI: $10.3390 /$ ijms21020515

78 Sommaggio R, Cappuzzello E, Dalla Pietà A, Tosi A, Palmerini $\mathrm{P}$, Carpanese D, Nicolè L and Rosato A: Adoptive cell therapy of triple negative breast cancer with redirected cytokine-induced killer cells. Oncoimmunology 9(1): 1777046, 2020. PMID: 32923140. DOI: 10.1080/2162402X.2020.1777046

79 Lee H, Kim YA, Kim Y, Park HS, Seo JH, Lee H, Gong G and Lee HJ: Clinicopathological factors associated with tumorinfiltrating lymphocyte reactivity in breast cancer. Cancer Immunol Immunother 69(11): 2381-2391, 2020. PMID: 32529292. DOI: $10.1007 / \mathrm{s} 00262-020-02633-5$

80 Wang ZX, Cao JX, Wang M, Li D, Cui YX, Zhang XY, Liu JL and Li JL: Adoptive cellular immunotherapy for the treatment of patients with breast cancer: a meta-analysis. Cytotherapy 16(7): 934-945, 2014. PMID: 24794183. DOI: 10.1016/j.jcyt.2014.02.011

81 Yang L, Lou M, Liu W, Feng D, Cheng $\mathrm{T}$ and Ma J: Amplification of immune cells derived from human peripheral blood and cytotoxicity on MDA-MB-231 breast cancer cells in vitro. Xi Bao Yu Fen Zi Mian Yi Xue Za Zhi 35(8): 682-688, 2019. PMID: 31638564

82 Shi YJ, Ren HY, Cen XN, Dong YJ, Ma MX, Zhao YL, Zhu Y and Yu JR: [Dendritic cells elicit cellular immune response by targeting to capture breast cancer cells]. Zhonghua Zhong Liu Za Zhi 30(2): 107-111, 2008. PMID: 18646691.

83 Pan K, Guan XX, Li YQ, Zhao JJ, Li JJ, Qiu HJ, Weng DS, Wang QJ, Liu Q, Huang LX, He J, Chen SP, Ke ML, Zeng YX and Xia JC: Clinical activity of adjuvant cytokine-induced killer cell immunotherapy in patients with post-mastectomy triplenegative breast cancer. Clin Cancer Res 20(11): 3003-3011, 2014. PMID: 24668644. DOI: 10.1158/1078-0432.CCR-14-0082

Received July 23, 2021

Revised August 29, 2021 Accepted September 23, 2021 